\title{
Biogeography rather than substrate type determines bacterial colonization dynamics of marine plastics
}

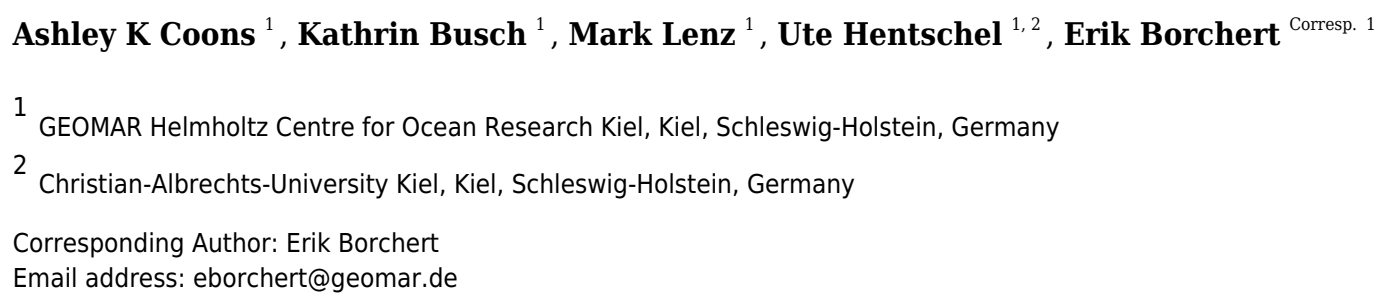

Since the middle of the 20th century, plastics have been incorporated into our everyday lives at an exponential rate. In recent years, the negative impacts of plastics, especially as environmental pollutants, have become evident. Marine plastic debris represents a relatively new and increasingly abundant substrate for colonization by microbial organisms, although the full functional potential of these organisms is yet to be uncovered. In the present study, we investigated plastic-type and incubation location as drivers of marine bacterial community structure development on plastics, i.e. the Plastisphere, via 16S rRNA amplicon analysis. Four distinct plastic types: high-density polyethylene (HDPE), linear low-density polyethylene (LDPE), polyamide (PA), polymethyl methacrylate (PMMA), and glass-slide controls were incubated for five weeks in the coastal waters of four different biogeographic locations (Cape Verde, Chile, Japan, South Africa) during July and August of 2019. The primary driver of the coastal Plastisphere composition was identified as incubation location, i.e. biogeography, while substrate type did not have a significant effect on bacterial community composition. The bacterial communities were consistently dominated by the classes Alphaproteobacteria, Gammaproteobacteria, and Bacteroidia, irrespective of sampling location or substrate type, however a core bacterial Plastisphere community was not observable at lower taxonomic levels. Overall, this study sheds light on the question of whether bacterial communities on plastic debris are shaped by the physicochemical properties of the substrate they grow on or by the marine environment in which the plastics are immersed. This study enhances the current understanding of biogeographic variability in the Plastisphere by including biofilms from plastics incubated in the previously uncharted Southern Hemisphere. 
1 Biogeography rather than substrate type determines bacterial colonization dynamics of 2 marine plastics

3 Ashley K. Coons ${ }^{1}$, Kathrin Busch ${ }^{1}$, Mark Lenz ${ }^{1}$, Ute Hentschel ${ }^{1,2}$, Erik Borchert ${ }^{1}$

$4{ }^{1}$ GEOMAR Helmholtz Centre for Ocean Research Kiel, Kiel, Schleswig-Holstein, Germany

$5 \quad{ }^{2}$ Christian-Albrechts University of Kiel, Kiel, Schleswig-Holstein, Germany

6

7 Corresponding Author:

8 Erik Borchert ${ }^{1}$

9 Hohenbergstraße 2, Kiel, Schleswig-Holstein, 24105, Germany

10 Email address: eborchert@geomar.de 


\section{Abstract}

12 Since the middle of the 20th century, plastics have been incorporated into our everyday lives at an exponential rate. In recent years, the negative impacts of plastics, especially as environmental

14 pollutants, have become evident. Marine plastic debris represents a relatively new and increasingly abundant substrate for colonization by microbial organisms, although the full functional potential of these organisms is yet to be uncovered. In the present study, we investigated plastic-type and incubation location as drivers of marine bacterial community structure development on plastics, i.e. the Plastisphere, via $16 S$ rRNA amplicon analysis. Four distinct plastic types: high-density polyethylene (HDPE), linear low-density polyethylene (LDPE), polyamide (PA), polymethyl methacrylate (PMMA), and glass-slide controls were incubated for five weeks in the coastal waters of four different biogeographic locations (Cape Verde, Chile, Japan, South Africa) during July and August of 2019. The primary driver of the coastal Plastisphere composition was identified as incubation location, i.e. biogeography, while substrate type did not have a significant effect on bacterial community composition. The bacterial communities were consistently dominated by the classes Alphaproteobacteria, Gammaproteobacteria, and Bacteroidia, irrespective of sampling location or substrate type, however, a core bacterial Plastisphere community was not observable at lower taxonomic levels. Overall, this study sheds light on the question of whether bacterial communities on plastic debris are shaped by the physicochemical properties of the substrate they grow on or by the marine environment in which the plastics are immersed. This study enhances the current understanding of biogeographic variability in the Plastisphere by including biofilms from plastics incubated in the previously uncharted Southern Hemisphere.

\section{Introduction}

Since the initial mass-production of plastics as inexpensive, single-use, sanitary health and convenience items during the 1950s, these synthetic polymers have been rapidly integrated into nearly every aspect of our daily lives. As of 2019, annual global plastic production exceeded 365 million metric tons (MT) (PlasticsEurope, 2020) and is widely recognized as a pollutant in virtually all environments - both terrestrial and aquatic, freshwater and marine (de Souza Machado et al., 2018; Harrison et al., 2018). It has been estimated that $3 \%$ of plastic produced annually enters the ocean each year, largely via riverine input, municipal wastewater effluent, and litter produced by urban tourism (Jambeck et al., 2015; Auta, Emenike \& Fauziah, 2017). 
42 Plastic debris often concentrates in oceanic gyres (Law et al., 2010), but has also been discovered 43 in remote regions, including Arctic Sea ice (Peeken et al., 2018), and at depths greater than 4000 44 meters in the Pacific Ocean (Krause et al., 2020). At first, the attention of the media and 45 scientists focused on the more apparent negative effects of larger plastic debris, including 46 entanglement and ingestion, in the marine environment (Laist, 1997). Throughout the past 47 decade, research efforts have shifted towards the ecological impacts of microplastics $(<5 \mathrm{~mm}$ 48 diameter; Arthur, Baker \& Bamford., 2009) on marine animals such as bivalves (Sussarellu et 49 al., 2016), fish (Lusher et al., 2016), and zooplankton (Cole et al., 2013), and the inevitable link 50 to humans through food web interactions (Cox et al., 2019). Most recently, concurrent with swift 51 advancements in molecular techniques, researchers have begun to describe the microbial life 52 colonizing marine plastic debris in an effort to clarify which microorganisms are present (Zettler, 53 Mincer \& Amaral-Zettler, 2013).

54 The moment debris comes into contact with the environment, a biofilm, defined as a community 55 of microorganisms that is attached to a surface (O'Toole, Kaplan \& Kolter, 2000), begins to form 56 (Dang \& Lovell, 2000). The term "Plastisphere" was coined by Zettler et al. (2013) to describe 57 the biofilm-forming communities on the surfaces of marine plastic debris - an immediate process 58 that encompasses different domains of life (Amaral-Zettler, Zettler \& Mincer, 2020). Most 59 Plastisphere research has highlighted findings of prokaryotic, especially bacterial diversity 60 (Wright, Langille \& Walker, 2020), although some reports of eukaryotic (Bryant et al., 2016; 61 Zaiko et al. 2016; Kettner et al., 2019; Oberbeckmann et al., 2014), including fungal (Gonda, 62 Jendrossek \& Molitoris, 2000; Kettner et al., 2017, Lacerda et al., 2020), diversity of mature 63 biofilms on marine plastic debris have been published.

64 Previous research investigating the bacterial Plastisphere has considered a variety of variables 65 that can potentially influence the formation and resulting composition of the biofilm community, 66 including substrate-type (Ogonowski et al., 2018; Kirstein et al., 2019; Oberbeckmann \& 67 Labrenz, 2020; Wright, Erni-Cassola, et al., 2020), biogeography (Oberbeckmann et al., 2014; 68 Amaral-Zettler et al., 2015), seasonality (Oberbeckmann et al., 2014), and age of biofilm 69 (Harrison et al., 2014; Wright, Langille \& Walker, 2020). Many distinct synthetic polymer types, 70 primarily polyethylene (PE), polypropylene (PP), polystyrene (PS), and polyethylene terephthalate (PET) (supplementary information; Wright, Langille \& Walker, 2020), have been 
72 utilized as polymer substrates to investigate the ecology of the Plastisphere. Marine plastic debris 73 is dominated by PP and PE (Erni-Cassola et al., 2019), the plastic types of the highest consumer 74 demand (PlasticsEurope, 2020). Current knowledge regarding the influence of biogeographic 75 location on microbial Plastisphere communities is focused on the Northern Hemisphere (Wright, 76 et al., 2020), while the Southern Hemisphere is so far scientifically underrepresented (Wright, 77 Langille \& Walker, 2020). Various experiments in coastal- and open-ocean surface waters have 78 been conducted, including the Pacific (Bryant et al., 2016, Zaiko et al., 2016, Tobias-Huenefeldt 79 et al., 2021), Atlantic (Debroas, Mone \& Ter Halle, 2017) and Indian Ocean (Muthukrishnan, A1 80 Khaburi \& Abed, 2019), as well as the Baltic (Oberbeckmann et al., 2014; Oberbeckmann, 81 Kreikemeyer \& Labrenz, 2018; Kesy et al., 2019), North (Oberbeckmann, Osborn \& Duhaime, 82 2016), and Mediterranean Sea (Dussud et al., 2018). Current research agrees that Plastisphere 83 communities differ significantly from the microbial assemblages found in the surrounding seawater (Amaral-Zettler, Zettler \& Mincer, 2020) and those present on naturally-occurring substrates, such as wood (Zettler, Mincer \& Amaral-Zettler, 2013). Certain bacterial phyla, such as Bacteroidota and Proteobacteria (Roager \& Sonnenschein, 2019), recur across geographic locations, including species of the potentially pathogenic Vibrio genus (Zettler, Mincer \& Amaral-Zettler, 2013; Kirstein et al., 2016; Debroas, Mone \& Ter Halle, 2017).

The aim of the present study was to determine whether, and to what extent, incubation location or plastic-type influence the bacterial community composition of marine plastic biofilms. Plasticcoated glass slides and plastic-free glass-slide controls were incubated for five weeks in the upper one meter of the coastal water column in four distinct marine locations (Cape Verde, region) were utilized to obtain insights into the bacterial colonization patterns on various plastic types at different locations. The results of this study expand our current understanding of taxonomic variability in microbial Plastisphere communities by including the marine biofilms originating from plastics incubated in the uncharted Southern Hemisphere.

Materials and methods

\section{Sample collection}

Plastic-coated glass slides were incubated at four sites globally by participants of the 
102 Experiments) following a standardized protocol in July and August 2019. Incubation locations

103 included Cape Verde, Chile, Japan, and South Africa (for exact locations see Fig. 1A)

104 Environmental parameters and sampling site characteristics can be found in the Supplementary

105 Table S1. Before marine exposure, one of four distinct synthetic polymer types, i.e. polyamide

106 (PA; PandaParticles UG, Erfurt, Germany), high-density polyethylene (HDPE; ExxonMobil),

107 linear low-density polyethylene (LDPE; ExxonMobil, Hamburg, Germany), polymethyl

108 methacrylate (PMMA; Kunststoff und Farben GmbH, Biebesheim, Germany), were individually

109 melted onto one side of glass microscope slides (Superfrost ${ }^{\circledR}$ Plus; Menzel GmbH,

110 Braunschweig, Germany) (Fig. 1B). The four different polymers were chosen based on their

111 classification as thermoplastics and therefore no chemical alteration due to the melting process

112 was expected. Furthermore, the four polymers can be distinguished by their buoyancy with

113 HDPE (density of $0.941 \mathrm{~g} / \mathrm{cm}^{3}$ ) and LDPE $\left(0.915-0.94 \mathrm{~g} / \mathrm{cm}^{3}\right.$ ) being positively buoyant and PA

$114\left(1.14 \mathrm{~g} / \mathrm{cm}^{3}\right)$ and PMMA $\left(1.18 \mathrm{~g} / \mathrm{cm}^{3}\right)$ being negatively buoyant. At each incubation location, ten

115 microscope slides, i.e. two slides of each polymer type plus two uncoated glass slides as controls,

116 were deployed vertically and at approximately one-meter depth in the coastal water column for

117 exactly five weeks, each individually secured with fishing line and an eight-gram weight to

118 guarantee vertical positioning. Upon sample collection, the slides were preserved in a

119 stabilization solution (25 mM sodium citrate, $20 \mathrm{mM}$ EDTA, $70 \mathrm{~g}$ ammonium sulfate per $100 \mathrm{ml}$,

$120 \mathrm{pH}$ 5.2) and sent to GEOMAR for subsequent DNA extraction. All genetic material was acquired

121 according to the Nagoya Protocol (Buck \& Hamilton, 2011) and the Convention on Biological

122 Diversity's (CBD) access and benefit-sharing (ABS) regulations (European Union, No 511/

123 2014). Field experiments were approved by Ministerio da Agricultura e Ambiente, Cabo Verde

124 (approval number 012/DNA/2021); Biodiversity and coastal research department of

125 environmental affairs, South Africa (approval number RES2019/96); Office for Mainstreaming

126 Biodiversity, Biodiversity Policy Division, Nature Conservation Bureau, Ministry of the

127 Environment, Japan; and Profesional Departamento de Conservación de Especies División de

128 Recursos Naturales y Biodiversidad, Ministerio del Medio Ambiente, Gobierno de Chile.

\section{Extraction of nucleic acids}

130 The mature biofilms, which accumulated on the incubated slides, were chemically digested using

131 an alkaline lysis buffer during a heat treatment (alkaline-lysis method; Kennedy et al., 2008). In

132 brief, the biological material scraped from the surface of each slide was mixed with pre-heated 
133 lysis buffer (100 mM Tris-HCl, 100 mM EDTA, $1.5 \mathrm{M} \mathrm{NaCl}, 1 \%$ CTAB, $2 \%$ SDS, pH 8.0) and

134 incubated in a water bath for two hours at $70^{\circ} \mathrm{C}$ with occasional mixing. The suspension was

135 subsequently centrifuged at $4^{\circ} \mathrm{C}$ at $13000 \mathrm{x}$ g for $30 \mathrm{~min}$, and the clear supernatant was

136 transferred to a fresh tube and mixed with $0.7 \times$ volume isopropanol. After at least $30 \mathrm{~min}$ of

137 incubation at room temperature, the mixture was centrifuged again and the resulting DNA pellet

138 was washed with $70 \%$ ethanol ( $\geq 99.8 \%$ denatured ethanol; Carl Roth $\AA$, Karlsruhe, Germany),

139 centrifuged, and air-dried before it was resuspended in a suitable amount of Tris-EDTA (TE)

140 buffer (10 mM Tris-HCl, $1 \mathrm{mM}$ EDTA). The quality and quantity of the extraction were

141 evaluated with a NanoDrop spectrophotometer (Desjardins \& Conklin, 2010). Using the 16S

142 rRNA gene primer pair 27F and 1492R, segments of the resulting DNA extracts were amplified

143 for a quality check via polymerase chain reaction (PCR), with the following PCR conditions: an

144 initial denaturation at $95^{\circ} \mathrm{C}$ for $3 \mathrm{~min}, 34$ cycles of $95^{\circ} \mathrm{C}$ for $30 \mathrm{~s}, 56^{\circ} \mathrm{C}$ for $30 \mathrm{~s}$, and $72^{\circ} \mathrm{C}$ for 90

$145 \mathrm{~s}$, followed by a final extension at $72^{\circ} \mathrm{C}$ for $5 \mathrm{~min}$ and held at $10^{\circ} \mathrm{C}$. The resulting PCR products

146 were visually assessed via $1 \%$ gel electrophoresis. For amplicon sequencing, the V3-V4

147 hypervariable region of the $16 \mathrm{~S}$ rRNA gene was amplified using primer pair $341 \mathrm{~F}$ (5'-

148 CCTACGGGAGGCAGCAG-3'; Muyzer, de Waal \& Uitterlinden, 1993) and 806R (5'-

149 GGACTACHVGGGTWTCTAAT-3'; Caporaso et al., 2011) with the cycler conditions as

150 follows: initial denaturation at $98^{\circ} \mathrm{C}$ for $30 \mathrm{~s}, 30$ cycles of $98^{\circ} \mathrm{C}$ for $9 \mathrm{~s}, 55^{\circ} \mathrm{C}$ for $60 \mathrm{~s}$, and $72^{\circ} \mathrm{C}$

151 for $90 \mathrm{~s}$, followed by a final extension at $72^{\circ} \mathrm{C}$ for $10 \mathrm{~min}$ and held at $10^{\circ} \mathrm{C}$. Sequencing of the

152 V3-V4 region of the $16 \mathrm{~S}$ rRNA gene was conducted using v3 chemistry on a MiSeq Illumina

153 sequencing platform at the Competence Centre for Genomic Analysis (CCGA) Kiel, Germany.

154 Quantitative Insights into Microbial Ecology (QIIME2) pipeline

155 Raw amplicon sequences were processed using the open-source Quantitative Insights into

156 Microbial Ecology (QIIME2) framework (version 2019.10; Bolyen et al., 2019) similar to the

157 procedures described by Busch et al. (2021). For this, forward primers and heterogeneity spacers

158 were trimmed from forward-only single-end fastq files using the cutadapt plugin (Martin, 2011).

159 The quality of the demultiplexed reads was verified using the quality-filter plugin for PHRED-

160 based filtering and trimming (Bokulich et al., 2013). Reads were denoised using the denoise-

161 single method of the DADA2 algorithm (Callahan et al., 2016), which truncated the 3' ends at

162270 base pairs, removed chimeric sequences, and inferred sample composition using a

163 parametric error model. Truncation at $270 \mathrm{nt}$ length increased the quality of the reads

Peer] reviewing PDF | (2021:04:60408:2:0:NEW 6 Aug 2021) 
164 significantly, but reduced the overlap between forward and reverse reads and therefore only 165 forward reads were used for the analysis.

166 Amplicon sequence variant (ASV; Callahan et al., 2017) taxonomy was classified at an $80 \%$

167 confidence level using the most recent SILVA 138 16S rRNA gene reference database (Quast et 168 al., 2013; Yilmaz et al., 2014) via the pre-fitted classify-sklearn taxonomy classifier method 169 (Pedregosa et al., 2012) of the feature-classifier plugin (Bokulich et al., 2018). Common 170 eukaryotic contaminants (chloroplasts, mitochondria) and unassigned sequences were removed 171 using the filter-features method of the feature-table plugin, then the filtered dataset was rarefied 172 to 8000 sequences due to a satisfactory saturation of the alpha rarefaction curves for this number 173 of features (see Supplementary Figure S1). A phylogenetic backbone tree was constructed using 174 both FastTree (Price, Dehal \& Arkin, 2009, 2010) and MAFFT (Katoh \& Standley, 2013) 175 alignment via the phylogeny plugin, and the resulting tree was used to compute core diversity 176 metrics. QIIME2 artifacts containing phylogenetic and non-phylogenetic diversity metrics were 177 computed for downstream analyses along with an alpha-rarefaction curve via the diversity 178 plugin. QIIME2 scripts can be found in the Supplementary File S1.

\section{Diversity measures}

180 Further statistical analyses were computed using the community ecology package vegan (version 181 2.5-6; Oksanen et al., 2010, 2019) and stats (version 3.6.2) within the open-source R

182 environment (version 3.6.2; R Core Team, 2019) using RStudio (version 1.1.453; RStudio Team, 183 2016), then graphically visualized with the aid of ggplot2 (version 3.3.0; Wickham, 2016) and

184 ggpubr (version 0.2.5; Kassambara, 2020). Some figures were further manipulated using the 185 open-source vector graphic editor Inkscape ${ }^{\mathrm{TM}}$ (version 0.94.4; Inkscape Project, 2019). The alpha 186 diversity within each group of the rarefied dataset was determined by the evenness (Pielou, 187 1966) and phylogenetic diversity (Faith’s PD; Faith \& Baker, 2006). Non-phylogenetic 188 (evenness) and phylogenetic (Faith's PD) diversity indices were visualized in violin plots to 189 assess alpha diversity when replicates were grouped by substrate type and location. All replicates 190 were included to compare between substrate types, although control replicates, i.e. communities 191 from plastic-free glass slides, were removed before analyzing the influence of location on 192 Plastisphere communities. The non-parametric Kruskal-Wallis rank sum test (Kruskal \& Wallis, 193 1952; Hollander \& Wolfe, 1973; Mcdonald, 2014) was implemented to determine whether the 
194 medians of the sample types differed significantly. If a significant result was observed, a

195 Wilcoxon pairwise comparison test (Mann \& Whitney, 1947) was performed with Benjamini \&

196 Hochberg correction (1995) to discover which sample types were different.

197 The data were explored for factors driving microbial community composition between sample

198 types with the assistance of the R package phyloseq (version 1.30.0; McMurdie \& Holmes,

199 2013). The qiime2R (version 0.99.21; Bisanz, 2018) package allowed for import of QIIME2

200 artifacts into $\mathrm{R}$ for the creation of a phyloseq object. Absolute count data were transformed into

201 compositional data with the pseq.rel function, then an ordination was performed on the

202 transformed phyloseq object using the non-metric multidimensional scaling method (NMDS;

203 Kruskal, 1964) with a sample-wise unweighted UniFrac distance matrix (Lozupone \& Knight,

204 2005). The visual interpretation of the NMDS plot was confirmed with a non-parametric,

205 permutational multivariate analysis of variance (PERMANOVA; Anderson, 2001, 2017) test.

206 The PERMANOVA group significance and pairwise tests were run simultaneously via the beta-

207 group-significance method (non-parametric MANOVA; Anderson, 2001) of the QIIME2

208 diversity plugin with an unweighted UniFrac matrix and 999 permutations. A significance level

209 of $\alpha=0.05$ was applied for all statistical analyses.

\section{Taxonomic composition analyses}

211 Bubble plots were used to display phyla that represented more than $0.01 \%$ of the medians of the

212 relative community composition per substrate type per incubation location. Furthermore, a

213 sunburst diagram was created to show the median relative composition of the families that made

214 up the most abundant bacterial phyla on plastic replicates. Taxonomic assignments on family

215 level responsible for less than $0.5 \%$ of the median relative abundance and order level with a

216 cumulative median relative abundance of less than $1 \%$ were removed and were then combined

217 at a higher taxonomic level. The web-based tool InteractiVenn (Heberle et al., 2015) produced a

218 Venn diagram to display ASVs distinct to or shared between plastic replicates from each

219 incubation location. The rarefied ASV table produced in QIIME2 was converted into a binary

220 presence-absence table using the feature-table plugin. The resulting biom table was exported and

221 converted to a tab-delimited file using the biom convert command, then ASVs with null values or

222 present in glass-slide controls were excluded. 


\section{Results}

\section{Sample overview}

225 In total, 36 samples from the four coastal incubation locations: Cape Verde $(\mathrm{n}=10)$; Chile $(\mathrm{n}=$ 226 8); Japan $(\mathrm{n}=8)$; South Africa $(\mathrm{n}=10)$ met quality control and minimum library size

227 requirements. The QIIME2 pipeline was completed with these 36 samples consisting of four 228 polymer types: HDPE $(\mathrm{n}=7)$, LDPE $(\mathrm{n}=7), \operatorname{PA}(\mathrm{n}=8), \operatorname{PMMA}(\mathrm{n}=7)$, and glass-slide controls $229(\mathrm{n}=7)$. Positive and negative sequencing controls were also removed. After quality control, 230 truncation (270 bp), removal of eukaryotic contaminants and unassigned reads, and subsampling 231 to the lowest number of reads (alpha rarefaction curve sufficiently saturated at 8000 features;

232 Fig. S1), 721330 non-chimeric sequences remained from the initial 949349 demultiplexed 233 Illumina reads with an average sequence frequency of 20036 reads across the 36 samples. The 234 reads were made up of 12361 unique features, which were taxonomically assigned according to 235 the SILVA single subunit (SSU) database release 138 (80\% confidence) (Quast et al., 2013; 236 Yilmaz et al., 2014). The observed ASVs per sample ranged from 403 to 1353 sequences. The 237 ASV and taxonomy table can be found in the Supplementary Tables S2 and S3.

\section{Diversity measures}

239 The Shannon diversity indices ranged from 7.6 to 9.7 per sample, Pielou's evenness from 0.57 to 2400.92 and Faith's PD from 35.1 to 98.3. Evenness (Kruskal-Wallis rank sum test: chi-squared = $2415.089, \mathrm{p}=0.278, \mathrm{df}=4)$ and cumulative phylogenetic diversity (chi-squared $=2.179, \mathrm{p}=0.703$, $242 \mathrm{df}=4$ ) of the bacterial communities did not vary significantly by substrate type (Fig. 2). Pielou's 243 evenness (chi-squared $=16.663, \mathrm{p}<0.001, \mathrm{df}=3)$ and Faith's PD $($ chi-squared $=13.649, \mathrm{p}=$ 244 0.003, df =3) did, however, vary significantly by location (Fig. 3). Pairwise Wilcoxon rank sum 245 tests revealed a significantly higher evenness of bacterial communities on plastic replicates from 246 Cape Verde, when compared to those from mid-latitudes (Chile, Japan, and South Africa)

247 (pairwise Wilcoxon tests: $\mathrm{p}<0.001$ ). Communities from Chile exhibited significantly lower 248 phylogenetic diversity than those from Cape Verde (pairwise Wilcoxon test: $p=0.028$ ), Japan ( $p$ $249=0.007)$, and South Africa $(\mathrm{p}=0.018)$. Communities from the two Northern Hemisphere 250 locations were not significantly different from one another phylogenetically (Cape Verde, Japan; $251 \mathrm{p}=1.0$ ), although they both displayed a significantly higher diversity than the assemblages from 252 the two Southern Hemisphere locations $(p=0.001$; Fig. S2). 
253 Bacterial Plastisphere communities clustered most clearly by location when visualized via

254 NMDS ordination (Fig. 4). A PERMANOVA test confirmed that location had a significant

255 influence on community composition (PERMANOVA: pseudo-F $=7.516, p=0.001$; Table 1A),

256 while substrate type did not (PERMANOVA: pseudo-F =0.637, $\mathrm{p}=0.999$; Table 1A). Pairwise,

257 non-parametric MANOVA tests revealed significant differences between all incubation locations

258 (MANOVA results; Table 1B).

259 Taxonomic composition analyses

260 The 12361 unique ASVs represented 49 bacterial phyla, and only $0.34 \%$ of these were not

261 classified beyond the kingdom level (Fig. 5). Proteobacteria were the most abundant phylum,

262 followed by Bacteroidota. Combined, the two phyla accounted for more than $65 \%$ of the

263 bacterial community of each sample, irrespective of substrate type or location (Fig. 5). Eleven

264 phyla accounted for $>93.1 \%$ of each community, in descending order: Proteobacteria (46\%-

$26581.2 \%)$, Bacteroidota (6.8\%-35.8\%), Verrucomicrobiota (0.7\%-12.1\%), Bdellovibrionota $(0.3 \%$ -

$2663.5 \%)$, Actinobacteriota ( $<0.1 \%-8.9 \%)$, Planctomycetota $(<0.1 \%-3.6 \%)$, Patescibacteria $(<0.1 \%$ -

$2673.7 \%)$, Desulfobacterota (0.2\%-4.2\%), Acidobacteriota $(<0.1 \%-7.1 \%)$, Myxococcota $(0.1 \%-3 \%)$,

268 and Cyanobacteria $(<0.1 \%-7.2 \%)$. Differences in the identity of the most abundant phyla were

269 more pronounced between incubation locations than between substrate types. The remaining 38

270 phyla accounted for less than $7 \%$ of the total bacterial diversity per sample.

271 Substrate type was not a significant driver of bacterial community composition (PERMANOVA,

$272 \mathrm{p}=0.999$; Table 1A). For this reason, glass-slide controls were removed from the analysis to

273 allow for family-level evaluation across all plastic replicates. Proteobacteria and Bacteroidota

274 were fully represented by the classes Alpha- and Gammaproteobacteria (14.9\% and $25.1 \%$ of

275 the median relative abundance, respectively), Bacteroidia (19.5\%), and a very small percentage

276 of Rhodothermia $(0.1 \%)$. Families accounting for $>0.5 \%$ of the median relative community

277 structure on plastics had a high level of overlap with previous studies on bacterial Plastisphere

278 communities (Fig. 6) (Amaral Zettler, Zettler \& Mincer, 2020).

279 ASVs found on glass slide controls were further removed to create an ASV-level comparison of 280 the bacterial communities present on plastic replicates between sampling locations (Fig. 7). The 281 resulting $7825 \mathrm{ASVs}$ present on the plastic polymer-coated slides were principally determined by 282 location. Japan accounted for the largest proportion of distinct ASVs (32.0\%), followed by Cape 
283 Verde (29.4 \%), South Africa (20.6\%), and Chile (14.1\%). An overlap in ASVs was not

284 observed between all four incubation locations. Excluding the equatorial Cape Verde location,

285 the three mid-latitude sites have 18 ASVs in common. Two of these ASVs were classified to

286 species level, and represent Ilumatobacter nonamiensis strain YM16-303 (Actinobacteriota; 99.4

287 \% confidence) and Portibacter lacus (Bacteroidota; $99.9 \%$ ). The remaining 16 ASVs were

288 classified to varying degrees, belonging mostly to Bacteroidota and Proteobacteria. The ASVs

289 belonging to Bacteroidota were classified to genus (Portibacter, 99.7 \%; Marinoscillum, $91.5 \%$;

290 Reichenbachiella, $99.9 \%$; Kordia, $99.9 \%$ ) or family level (Cryomorphaceae, $99.9 \%$;

291 Flavobacteriaceae, $99.9 \%$ ). The ASVs that belonged to Proteobacteria were classified to genus

292 (Kordiimonas $99.9 \%$; Altererythrobacter, $80.9 \%$; Pseudoalteromonas, $98.4 \%$; Woeseia, 99.5

$293 \%$ ), order (Xanthomonadales, $86.5 \%$ ), and class level (Gammaproteobacteria, $99.9 \%$ ). The four

294 remaining ASVs were classified to genus level: SM1 A02 (Planctomycetota; 98.3 \%), R76-B128

295 (Verrucomicrobiota; $99.9 \%$ ), and Haloferula (Verrucomicrobiota; $96.3 \%$ ), plus one order-level

296 classification: Bradymonadales (Desulfobacterota; $95.0 \%$ ). These four ASVs could be further

297 identified by NCBI BLAST to be related to the genera Phycisphaera, Kiritimatiella, Haloferula

298 and Nitrospina, respectively (see Supplementary Table S4 for all BLAST results). Furthermore,

299 each location was investigated for ASV distribution among the different plastic types excluding

300 the ASVs also found on the glass control slides (supplementary Figure S3). At each location

301 several unique ASVs were found per plastic type.

\section{Discussion}

\section{Influence of incubation location on bacterial community composition}

304 The coordinated incubation of plastic-coated glass slides allowed for a comparison of marine

305 bacterial Plastisphere communities between four distinct incubation locations (Cape Verde,

306 Chile, Japan, South Africa) distributed between Earth's two largest oceans (Atlantic and Pacific)

307 and in both hemispheres. Well-documented research regarding marine diversity in surface waters

308 has revealed high diversity near continental margins, which decreases longitudinally towards

309 open-ocean environments (Gray, 1997) and latitudinally towards the poles for microbial

310 organisms (Martiny et al., 2006; Fuhrman et al., 2008; Tara Oceans: Ibarbalz et al., 2019 \&

311 Salazar et al., 2019). Parallel trends were reflected in this study, suggesting a larger influence of

312 the biogeographic location than substrate type on bacterial Plastisphere community structure.

313 When averaged across all polymer types, plastic-coated glass slides from all locations were 
314 similar in evenness (Fig. 2), while, when averaged across all substrate types, the communities

315 from the equator (Cape Verde) had a significantly higher evenness than the mid-latitude

316 incubation locations (Chile, Japan, South Africa) (Fig. 3). Here, temporal variation in

317 environmental variables is characteristically less pronounced than in temperate or polar regions

318 (Bunse \& Pinhassi, 2017). In contrast to this, the phylogenetic diversity of the communities that 319 established on the plastic-coated slides varied between locations and was significantly lower on 320 slides from the Southern Hemisphere (Fig. S2). This was likely due to the colder temperatures in

321 the austral winter (Gilbert et al., 2012), with communities from Chile having the lowest

322 phylogenetic diversity coupled with the most southern position. Temperature was recently

323 deemed the best predictor of bacterial diversity in surface waters (Ibarbalz et al., 2019), but we

324 would need to repeat our study during the austral summer and record environmental

325 measurements to verify whether temperature is the best explanation for the pattern we observed.

326 When examining the beta diversity of the bacterial communities, the ordination technique we

327 used displayed a distinct clustering of samples by incubation location. Statistical testing further

328 confirmed that the incubation location played the largest role in determining microbial

329 community structure. This has previously been observed on a more regional scale along a

330 salinity gradient in the Baltic Sea (Oberbeckmann, Kreikemeyer \& Labrenz, 2018), and between

331 open-ocean samples from the Northern Atlantic Gyre and the Northern Pacific Subtropical Gyre

332 (Zettler, Mincer \& Amaral-Zettler, 2013; Bryant et al., 2016). In our study, bacterial

333 communities from plastic-coated slides that were incubated at Northern Hemisphere locations

334 (Cape Verde, Japan) had more distinct ASV signatures (29.4\% and $32.0 \%$, respectively) than

335 those from the Southern Hemisphere. Although replicates from each location in this study

336 clustered separately, those from the Southern Hemisphere (Chile, South Africa) were more

337 similar to each other than those from the Northern Hemisphere, potentially indicating

338 hemisphere, i.e. seasonal influence, to act as a secondary driver of bacterial community

339 composition, which has been suggested previously on a regional scale (Oberbeckmann et al.,

340 2014). In summary, our study magnifies regional, spatial, and temporal trends on a more global

341 scale.

342 Implications of incubation location dependencies are important with respect to the identification

343 of potential plastic degrading bacteria. We investigated the presence/absence of certain bacterial 
344 groups with respect to hydrocarbon degrading bacteria, mentioned in recent literature (Urbanek,

345 Rymowicz \& Mirończuk, 2018; Danso, Chow \& Streit, 2019). We found some interesting

346 patterns, but cannot conclude any plastic degrading capabilities from our amplicon data alone.

347 Alcanivorax is part of the obligate hydrocarbonoclastic bacteria (OHCB) group (Cafaro et al.

348 2013) and is for example differentially abundant in our dataset and almost exclusively found in

349 South Africa and Cape Verde, other members like Ketobacter were absent only from the Chilean

350 sampling location, but on the other hand Oleiphilus was found at all sampling locations. Other

351 bacteria expected to be involved in plastic degradation, such as Erythrobacter (absent from Cape

352 Verde) and Arcobacter (mainly present in Chile) are also present only at some locations

353 (Urbanek, Rymowicz \& Mirończuk, 2018), hinting to the Baas Becking hypothesis “everything

354 is everywhere but the environment selects" (1934), as no particular enrichment was apparent.

\section{Influence of plastic-type on bacterial community composition}

356 No significant differences in the alpha diversity (Pielou's evenness, Faith's PD) of the bacterial 357 communities that established on the different substrate types (HDPE, LDPE, PA, PMMA, glass-

358 slide controls) were detected after five weeks of incubation in the coastal water column. In this

359 study, however, the pooled control replicates exhibited the largest within-group variation in

360 diversity of all substrate types. This could indicate that the set of bacteria that can colonize

361 plastics is less diverse than those that can establish on other and more natural substrates (e.g.

362 driftwood, seaweed, rocks). Additionally, the mean phylogenetic diversity of the communities

363 that established on the HDPE replicates was slightly lower than those that colonized the other

364 substrates. This could have been driven by the general hydrophobicity of the polymer, as PE

365 ranks among the most hydrophobic polymers, which are also the least vulnerable to enzymatic

366 attack (Min, Cuiffi \& Mathers, 2020). Furthermore, HDPE is characterized by a higher degree of

367 crystallinity in comparison to LDPE further impeding potential microbial colonization and

368 enzymatic accessibility. The inherent buoyancy of each polymer type had no apparent influence

369 on colonization patterns here. Nonetheless, it needs to be noted that positively buoyant polymers

370 like HDPE and LDPE have a much greater potential for dispersion in the marine environment

371 than negatively buoyant polymers like PA and PMMA, perhaps leading to different colonization

372 patterns if not fixed to one location as done in this study. Pabortsava and Lampitt (2020) identify

373 PE particles as the most abundant microplastic in the upper water layer in the Atlantic Ocean in

374 comparison to polypropylene and polystyrene, supporting its dispersion potential. 
375 Previous research has reached a consensus that the biofilm-forming bacterial communities found

376 on plastics differ significantly from those found free-living in seawater (see review, Amaral-

377 Zettler, Zettler \& Mincer, 2020) or on natural substrates, such as wood (Zettler, Mincer \&

378 Amaral-Zettler, 2013; Ogonowski et al., 2018). In this study, no significant difference in

379 community composition between the polymer types was observed, a finding that is both

380 corroborated (Oberbeckmann, Kreikemeyer \& Labrenz, 2018; Oberbeckmann \& Labrenz, 2020;

381 Dudek et al., 2020) and challenged (Lobelle \& Cunliffe, 2011; Kirstein et al., 2016, 2019) by

382 earlier research. Oberbeckmann et al. (2014) suggested that communities at early time points in

383 the colonization process are more likely to reveal polymer-specificity, while communities that

384 establish on different polymers should gradually converge over time as the biofilms mature

385 (Harrison et al., 2014). Plastic-specific patterns in bacterial community composition have

386 emerged during incubations as short as two minutes (Harrison et al., 2014) and two weeks

387 (Ogonowski et al., 2018), but also after 21 months of incubation when closely attached, mature

388 biofilms were selectively enriched under controlled conditions (Kirstein et al., 2019). Generally,

389 it has been agreed that polymer type plays a minor role in determining bacterial Plastisphere

390 community composition once a mature biofilm has formed, especially when compared to

391 biogeography (Oberbeckmann \& Labrenz, 2020). Since in our study the substrates were

392 incubated for five weeks, it could be that any initially existing differences between the polymers

393 and/or between polymers and glass disappeared during the course of biofilm maturation.

\section{Bacterial diversity of the Plastisphere}

395 The data presented here demonstrate that two bacterial phyla, Proteobacteria (classes

396 Alphaproteobacteria and Gammaproteobacteria) and Bacteroidota (class Bacteroidia), dominated

397 the bacterial communities across all substrate types, irrespective of incubation location. A recent

398 meta-analysis, which reanalyzed $16 \mathrm{~S}$ rRNA gene amplicon data from 35 Plastisphere studies,

399 revealed the successive colonization of the Plastisphere (Wright, Langille \& Walker, 2020). The

400 authors found that Alphaproteobacteria are significantly more abundant at early time points of

401 succession, while, at a later stage, a significant increase in Bacteroidia usually coincides with the

402 arrival of Gammaproteobacteria. Previous findings of bacterial Plastisphere communities have a

403 high level of taxonomic overlap with this study (Zettler, Mincer \& Amaral-Zettler, 2013; Bryant

404 et al., 2016; Oberbeckmann, Osborn \& Duhaime, 2016; Kesy et al., 2019). Many of the taxa that

405 were found to be highly abundant on the marine-incubated plastic-coated slides were also 
406 prevalent on plastics that were retrieved from the North Atlantic Gyre (Zettler, Mincer \& 407 Amaral-Zettler, 2013) and on those that were incubated for five weeks in the North Sea 408 (Oberbeckmann, Osborn \& Duhaime, 2016). Common community members include bacteria that 409 prefer a surface-attached lifestyle, i.e. Flavobacteriaceae (Zheng et al., 2018) and Saprospiraceae 410 (McIlroy \& Nielsen, 2014), opportunistic colonizers (Rhodobacteriaceae; Dang \& Lovell, 2016), 411 and biofilm formers (Hyphomonodaceae; Abraham \& Rohde, 2014), which made up 11.66 \%, $4122.64 \%, 8.80 \%$, and $1.62 \%$ of the median bacterial community composition in this study, 413 respectively. Other recurring members of proteobacterial biofilms on plastics, such as the orders 414 Alteromonadales (Zettler, Mincer \& Amaral-Zettler, 2013), Oceanospirillales (Roager \& 415 Sonnenschein, 2019), and Cellvibronaceae (Oberbeckmann \& Labrenz, 2020; Cheng et al., 2021) 416 represented $2.20 \%, 2.67 \%$, and $0.60 \%$ of the median relative community structure, 417 respectively. Micavibrionaceae $(0.54 \%)$ was recently described as a PA-specific community 418 member (Di Pippo et al., 2020), while Miao et al., (2019) associated Cyclobacteriaceae (2.51 \%) 419 with PE and PP. Gammaproteobacterial families with median relative abundances $>0.5 \%$, 420 which were detected in our study but were not previously documented as members of bacterial 421 Plastisphere communities, included: Halieaceae (6.04\%), Arenicellales (0.93\%), and 422 Spongiibacteraceae $(0.68 \%)$.

423 Bacteria of the genus Vibrio are ubiquitous in the marine environment (Vezzulli et al., 2012). 424 Concerning plastic surfaces, Vibrio have been described as pathogenic "hitchhikers", profiting 425 from the abundance of debris available to aid in their dispersal (Zettler, Mincer \& Amaral426 Zettler, 2013; Kirstein et al., 2016; Debroas, Mone \& Ter Halle, 2017), while other Vibrio 427 species have been suggested as promising candidates for the remediation of plastics (Danso, 428 Chow \& Streit, 2019). Of the many Vibrio species, 12 are categorized as human pathogens 429 (Kokashvili et al., 2015). In this study, Vibrio accounted for $0.82 \pm 0.94 \%$ of the bacterial 430 Plastisphere community, although most were not classified to the species level. The classified 431 Vibrio species were assigned to Vibrio sp. 343 and CQB-15, V. gallaecius, and V. breoganii, the 432 latter preferring a vegetarian (microalgal) diet (Corzett et al., 2018). None of the Vibrio in our 433 study are categorized as human pathogens. Our results align with those of Kesy et al., (2019) and 434 Oberbeckmann et al. (2018, 2020), who suggest that most Vibrio species represent opportunistic 435 biofilm generalists that favor natural substrates, such as wood, over plastic particles.

436 Microplastics are more and more discussed as potential vectors for microorganisms, especially 
437 pathogens, multidrug resistant strains and as vectors for chemical pollutants (Shen et al., 2019).

438 Song and colleagues (2020) incubated particles (HDPE, tyre wear, wood) along a salinity

439 gradient from a river to an offshore island in north west Germany sequentially to reconstruct a

440 potential transport of microorganisms, focusing on multidrug resistant Escherichia coli strains.

441 This study approach could be applied on a wider scale to allow for more general statements on

442 microplastics as vectors, but concluded that there is only a low likelihood for dissemination of

443 multidrug resistant E. coli via plastic particles.

444 Overall, at the ASV-level, we found no evidence for a global "core" bacterial Plastisphere 445 community. Most previous studies defined "core" microbiomes according to OTUs (Kesy et al., 446 2019; Oberbeckmann, Kreikemeyer \& Labrenz, 2018). Traditional OTU (operational taxonomic 447 units) picking strategies usually cluster reads with less than $3 \%$ dissimilarity as one bacterial 448 taxon (one OTU), hence, lose resolution and artificially increase the probability of finding a 449 "core" microbiome. Nevertheless, certain taxonomic groups undoubtedly and consistently 450 recurred on marine-incubated plastics in this study, regardless of the geographic location from 451 which the plastic originated, and this may indicate the presence of a functional core microbiome, 452 though this was not directly tested. Furthermore, when looking at the local scale, we found a 453 number of unique ASVs per polymer type at each location. This hints towards polymer-specific 454 Plastispheres rather than towards a "core" bacterial Plastisphere, which is the same across 455 polymer types and locations (supplementary Figure S3), but the investigated number of samples 456 was too small for a robust statistic testing of this hypothesis.

\section{Conclusions}

458 Our $16 S$ rRNA gene amplicon-based study expands the current knowledge about variability in 459 the composition of bacterial Plastisphere communities by including samples from the previously 460 uncharted Southern Hemisphere. Our findings are consistent with previous reports that there is 461 not a defined "global" Plastisphere community but rather many Plastisphere communities, whose 462 community development and compositions are driven primarily by local and location-specific 463 influences. Although, no significant difference in bacterial community composition was detected 464 between the plastic types used in our study, two bacterial phyla (Proteobacteria and Bacteroidia) 465 dominated the community structure of all replicates, irrespective of incubation location or 466 polymer type. 


\section{Acknowledgements}

468 Biofilm samples for this study were collected by student participants and scientists of the 469 international research and student training program GAME (Global Approach by Modular

470 Experiments). These were Paulo Vasconcelos, Leo Gottschalck and Corrine Almeida (Cape

471 Verde), Abril Sánchez, Jonas Barkhau and Martin Thiel (Chile), Daphné Houiller, Uki Kawata

472 and Masahiro Nakaoka (Japan), Matthew Germizhuisen, Silja Blechschmidt and Maya Pfaff

473 (South Africa). We would also like to thank Ina Clefsen and Andrea Hethke, for their thorough

474 and reliable laboratory assistance. We acknowledge financial support by DFG within the funding 475 program Open Access Publizieren.

\section{Competing interest}

477 The authors declare there are no competing interests.

\section{Author contributions}

479 EB, ML, and UH developed the conceptual idea of the study and the sampling was conducted 480 with the GAME project led by ML. AKC performed the bioinformatic analysis with a pipeline 481 designed by $\mathrm{KB}$. KB and $\mathrm{EB}$ aided in results interpretation. AKC and EB wrote the manuscript. $482 \mathrm{AKC}, \mathrm{UH}, \mathrm{KB}, \mathrm{ML}$, and $\mathrm{EB}$ reviewed and edited the manuscript. This publication is based on 483 AKC's Master thesis, which was submitted to the University of Kiel.

\section{Data availability}

485 All raw 16S rRNA gene amplicon reads were deposited along with sample metadata and 486 attributes in the National Center for Biotechnology Information (NCBI) Sequence Read Archive 487 (SRA) database under BioProject ID: PRJNA720815; BioSample accessions: SAMN18680242488 SAMN18680277.

\section{$489 \quad$ Funding}

490 This work was supported by PLASTISEA as part of the BMBF Funding Activity 'New

491 Biotechnological Processes based on Marine Resources-BioProMare' 2020-2023 (Funding 492 Reference Number: 031B0867A) (awarded to UH and EB).

\section{References}

494 Abraham, W.-R., \& Rohde, M. (2014). The Family Hyphomonadaceae. In E. Rosenberg, E. F. 495 DeLong, S. Lory, E. Stackebrandt, \& F. Thompson (Eds.), The Prokaryotes: 
496

497

498

499

500

501

502

503

504

505

506

507

508

509

510

511

512

513

514

515

516

517

518

519

520

521

522

523

524

525

526

Alphaproteobacteria and Betaproteobacteria (pp. 283-299). Springer Berlin Heidelberg. https://doi.org/10.1007/978-3-642-30197-1_260

Amaral-Zettler, L. A., Zettler, E. R., \& Mincer, T. J. (2020). Ecology of the plastisphere. In Nature Reviews Microbiology. Nature Research. https://doi.org/10.1038/s41579-019-0308-0

Amaral-Zettler, L. A., Zettler, E. R., Slikas, B., Boyd, G. D., Melvin, D. W., Morrall, C. E., Proskurowski, G., \& Mincer, T. J. (2015). The biogeography of the Plastisphere: Implications for policy. Frontiers in Ecology and the Environment, 13(10), 541-546. https://doi.org/10.1890/150017

Anderson, M. J. (2001). A new method for non-parametric multivariate analysis of variance. Austral Ecology, 26(1), 32-46. https://doi.org/10.1111/j.1442-9993.2001.01070.pp.x

Anderson, M. J. (2017). Permutational Multivariate Analysis of Variance (PERMANOVA). In Wiley StatsRef: Statistics Reference Online (pp. 1-15). John Wiley \& Sons, Ltd. https://doi.org/10.1002/9781118445112.stat07841

Arthur, C., Baker, J., \& Bamford, H. (2009). Proceedings of the International Research Workshop on the Occurrence, Effects and Fate of Microplastic Marine Debris. National Oceanic and Atmospheric Administration Technical Memorandum NOS-OR\&R-30.

Auta, H. S., Emenike, C. U., \& Fauziah, S. H. (2017). Distribution and importance of microplastics in the marine environment: A review of the sources, fate, effects, and potential solutions. Environment International, 102, 165-176. https://doi.org/10.1016/j.envint.2017.02.013

Benjamini, Y., \& Hochberg, Y. (1995). Controlling the False Discovery Rate: A Practical and Powerful Approach to Multiple Testing. Journal of the Royal Statistical Society: Series B (Methodological), 57(1), 289-300. https://doi.org/10.1111/j.2517-6161.1995.tb02031.x

Bisanz, J. E. (2018). qiime2R: Importing QIIME2 artifacts and associated data into $R$ sessions (v0.99). Unpublished.

Bokulich, N. A., Kaehler, B. D., Rideout, J. R., Dillon, M., Bolyen, E., Knight, R., Huttley, G. A., \& Gregory Caporaso, J. (2018). Optimizing taxonomic classification of marker-gene amplicon sequences with QIIME 2's q2-feature-classifier plugin. Microbiome, 6(1), 1-17. https://doi.org/10.1186/s40168-018-0470-z

Bokulich, N. A., Subramanian, S., Faith, J. J., Gevers, D., Gordon, J. I., Knight, R., Mills, D. A., \& Caporaso, J. G. (2013). Quality-filtering vastly improves diversity estimates from Illumina amplicon sequencing. Nature Methods, 10(1), 57-59. https://doi.org/10.1038/nmeth.2276 
527 Bolyen, E., Rideout, J. R., Dillon, M. R., Bokulich, N. A., Abnet, C. C., Al-Ghalith, G. A., 528 Alexander, H., Alm, E. J., Arumugam, M., Asnicar, F., Bai, Y., Bisanz, J. E., Bittinger, K., 529 Brejnrod, A., Brislawn, C. J., Brown, C. T., Callahan, B. J., Caraballo-Rodríguez, A. M., 530 Chase, J., ... Caporaso, J. G. (2019). Reproducible, interactive, scalable and extensible

531

532

533

534

535

536

537

538

539

540

541

542

543

544

545

546

547

548

549

550

551

552

553

554

555

556

557 microbiome data science using QIIME 2. In Nature Biotechnology (Vol. 37, Issue 8, pp. 852857). Nature Publishing Group. https://doi.org/10.1038/s41587-019-0209-9

Bryant, J. A., Clemente, T. M., Viviani, D. A., Fong, A. A., Thomas, K. A., Kemp, P., Karl, D. M., White, A. E., \& DeLong, E. F. (2016). Diversity and Activity of Communities Inhabiting Plastic Debris in the North Pacific Gyre. MSystems, 1(3). https://doi.org/10.1128/msystems.00024-16

Buck, M., \& Hamilton, C. (2011). The Nagoya Protocol on Access to Genetic Resources and the Fair and Equitable Sharing of Benefits Arising from their Utilization to the Convention on Biological Diversity. Review of European Community \& International Environmental Law, 20(1), 47-61. https://doi.org/10.1111/j.1467-9388.2011.00703.x

Bunse, C., \& Pinhassi, J. (2017). Marine Bacterioplankton Seasonal Succession Dynamics. In Trends in Microbiology (Vol. 25, Issue 6, pp. 494-505). Elsevier Ltd. https://doi.org/10.1016/j.tim.2016.12.013

Busch, K., Taboada, S., Riesgo, A., Koutsouveli, V., Ríos, P., Cristobo, J., Franke, A., Getzlaff, K., Schmidt, C., Biastoch, A., \& Hentschel, U. (2021). Population connectivity of fan-shaped sponge holobionts in the deep Cantabrian Sea. Deep-Sea Research Part I: Oceanographic Research Papers, 167, 103427. https://doi.org/10.1016/j.dsr.2020.103427

Cafaro, V., Izzo, V., Notomista, E., \& Di Donata, A. (2013). Marine hydrocarbonoclastic bacteria. In Marine Enzymes for Biocatalysis (p. 373-402). Woodhead publishing series in biomedicine. https://doi.org/10.1533/9781908818355.3.373

Callahan, B. J., McMurdie, P. J., \& Holmes, S. P. (2017). Exact sequence variants should replace operational taxonomic units in marker-gene data analysis. ISME Journal, 11(12), 2639-2643. https://doi.org/10.1038/ismej.2017.119

Callahan, B. J., McMurdie, P. J., Rosen, M. J., Han, A. W., Johnson, A. J. A., \& Holmes, S. P. (2016). DADA2: High-resolution sample inference from Illumina amplicon data. Nature Methods, 13(7), 581-583. https://doi.org/10.1038/nmeth.3869

Caporaso, J. G., Lauber, C. L., Walters, W. A., Berg-Lyons, D., Lozupone, C. A., Turnbaugh, P. 
558

559

560

561

562

563

564

565

566

567

568

569

570

571

572

573

574

575

576

577

578

579

580

581

582

583

584

585

586

587

588

J., Fierer, N., \& Knight, R. (2011). Global patterns of 16S rRNA diversity at a depth of millions of sequences per sample. Proceedings of the National Academy of Sciences of the United States of America, 108 Suppl 1(Supplement 1), 4516-4522. https://doi.org/10.1073/pnas.1000080107

Cheng, J., Jacquin, J., Conan, P., Pujo-Pay, M., Barbe, V., George, M., Fabre, P., Bruzaud, S., Ter Halle, A., Meistertzheim, A.-L., \& Ghiglione, J.-F. (2021). Relative Influence of Plastic Debris Size and Shape, Chemical Composition and Phytoplankton-Bacteria Interactions in Driving Seawater Plastisphere Abundance, Diversity and Activity. Frontiers in Microbiology, 11, 3430. https://doi.org/10.3389/fmicb.2020.610231

Cole, M., Lindeque, P., Fileman, E., Halsband, C., Goodhead, R., Moger, J., \& Galloway, T. S. (2013). Microplastic ingestion by zooplankton. Environmental Science and Technology, 47(12), 6646-6655. https://doi.org/10.1021/es400663f

Corzett, C. H., Elsherbini, J., Chien, D. M., Hehemann, J. H., Henschel, A., Preheim, S. P., Yu, X., Alm, E. J., \& Polz, M. F. (2018). Evolution of a vegetarian vibrio: Metabolic specialization of Vibrio breoganii to macroalgal substrates. Journal of Bacteriology, 200(15). https://doi.org/10.1128/JB.00020-18

Cox, K. D., Covernton, G. A., Davies, H. L., Dower, J. F., Juanes, F., \& Dudas, S. E. (2019). Human Consumption of Microplastics. Environmental Science \& Technology, 53(12), 70687074. https://doi.org/10.1021/acs.est.9b01517

Dang, H., \& Lovell, C. R. (2000). Bacterial primary colonization and early succession on surfaces in marine waters as determined by amplified rRNA gene restriction analysis and sequence analysis of 16S rRNA genes. Applied and Environmental Microbiology, 66(2), 467-475. https://doi.org/10.1128/AEM.66.2.467-475.2000

Dang, H., \& Lovell, C. R. (2016). Microbial Surface Colonization and Biofilm Development in Marine Environments. Microbiology and Molecular Biology Reviews, 80(1), 91-138. https://doi.org/10.1128/mmbr.00037-15

Danso, D., Chow, J., \& Streit, W. R. (2019). Plastics: Environmental and biotechnological perspectives on microbial degradation. In Applied and Environmental Microbiology (Vol. 85, Issue 19). American Society for Microbiology. https://doi.org/10.1128/AEM.01095-19

de Souza Machado, A. A., Kloas, W., Zarfl, C., Hempel, S., \& Rillig, M. C. (2018). Microplastics as an emerging threat to terrestrial ecosystems. In Global Change Biology (Vol. 24, Issue 4, 
589

590

591

592

593

594

595

596

597

598

599

600

601

602

603

604

605

606

607

608

609

610

611

612

613

614

615

616

617

618

619

pp. 1405-1416). Blackwell Publishing Ltd. https://doi.org/10.1111/gcb.14020

Debroas, D., Mone, A., \& Ter Halle, A. (2017). Plastics in the North Atlantic garbage patch: A boat-microbe for hitchhikers and plastic degraders. Science of The Total Environment, 599600, 1222-1232. https://doi.org/https://doi.org/10.1016/j.scitotenv.2017.05.059

Desjardins, P., \& Conklin, D. (2010). NanoDrop microvolume quantitation of nucleic acids. Journal of Visualized Experiments, 45. https://doi.org/10.3791/2565

Di Pippo, F., Venezia, C., Sighicelli, M., Pietrelli, L., Di Vito, S., Nuglio, S., \& Rossetti, S. (2020). Microplastic-associated biofilms in lentic Italian ecosystems. Water Research, 187, 116429. https://doi.org/10.1016/j.watres.2020.116429

Dudek, K. L., Cruz, B. N., Polidoro, B., \& Neuer, S. (2020). Microbial colonization of microplastics in the Caribbean Sea. Limnology and Oceanography Letters, 5(1), 5-17. https://doi.org/10.1002/lol2.10141

Dussud, C., Hudec, C., George, M., Fabre, P., Higgs, P., Bruzaud, S., Delort, A.-M., Eyheraguibel, B., Meistertzheim, A.-L., Jacquin, J., Cheng, J., Callac, N., Odobel, C., Rabouille, S., \& Ghiglione, J.-F. (2018). Colonization of Non-biodegradable and Biodegradable Plastics by Marine Microorganisms. Frontiers in Microbiology, 9, 1571. https://doi.org/10.3389/fmicb.2018.01571

Erni-Cassola, G., Zadjelovic, V., Gibson, M. I., \& Christie-Oleza, J. A. (2019). Distribution of plastic polymer types in the marine environment; A meta-analysis. Journal of Hazardous Materials, 369, 691-698. https://doi.org/10.1016/j.jhazmat.2019.02.067

Faith, D. P., \& Baker, A. M. (2006). Phylogenetic Diversity (PD) and Biodiversity Conservation: Some Bioinformatics Challenges. Evolutionary Bioinformatics, 2, 117693430600200. https://doi.org/10.1177/117693430600200007

Fuhrman, J. A., Steele, J. A., Hewson, I., Schwalbach, M. S., Brown, M. V, Green, J. L., \& Brown, J. H. (2008). A latitudinal diversity gradient in planktonic marine bacteria. Proceedings of the National Academy of Sciences, 105(22), 7774 LP - 7778. https://doi.org/10.1073/pnas.0803070105

Gilbert, J. A., Steele, J. A., Caporaso, J. G., Steinbrück, L., Reeder, J., Temperton, B., Huse, S., McHardy, A. C., Knight, R., Joint, I., Somerfield, P., Fuhrman, J. A., \& Field, D. (2012). Defining seasonal marine microbial community dynamics. ISME Journal, 6(2), 298-308. https://doi.org/10.1038/ismej.2011.107 
620 Gonda, K. E., Jendrossek, D., \& Molitoris, H. P. (2000). Fungal degradation of the thermoplastic 621 polymer poly- $\beta$-hydroxybutyric acid (PHB) under simulated deep sea pressure. 622 Hydrobiologia, 426(1), 173-183. https://doi.org/10.1023/A:1003971925285

623

624

625

626

627

628

629

630

631

632

633

634

635

636

637

638

639

640

641

642

643

644

645

646

647

648

649

650

Gray, J. S. (1997). Marine biodiversity: Patterns, threats and conservation needs. Biodiversity and Conservation, 6(1), 153-175. https://doi.org/10.1023/A:1018335901847

Harrison, J. P., Hoellein, T. J., Sapp, M., Tagg, A. S., Ju-Nam, Y., \& Ojeda, J. J. (2018). Microplastic-associated biofilms: A comparison of freshwater and marine environments. In Handbook of Environmental Chemistry (Vol. 58, pp. 181-201). Springer Verlag. https://doi.org/10.1007/978-3-319-61615-5_9

Harrison, J. P., Schratzberger, M., Sapp, M., \& Osborn, A. M. (2014). Rapid bacterial colonization of low-density polyethylene microplastics in coastal sediment microcosms. BMC Microbiology, 14(1), 232. https://doi.org/10.1186/s12866-014-0232-4

Heberle, H., Meirelles, V. G., da Silva, F. R., Telles, G. P., \& Minghim, R. (2015). InteractiVenn: A web-based tool for the analysis of sets through Venn diagrams. BMC Bioinformatics, 16(1), 169. https://doi.org/10.1186/s12859-015-0611-3

Hollander, M., \& Wolfe, D. A. (1973). Nonparametric statistical methods. Wiley.

Tobias-Huenefeldt, S. P., Wenley, J., Baltar, F. \& Morales, S. E. (2021). Ecological drivers switch from bottom-up to top-down during microbial community successions. ISME Journal, 15, 1085-1097. https://doi.org/10.1038s41396-020-00833-6

Ibarbalz, F. M., Henry, N., Brandão, M. C., Martini, S., Busseni, G., Byrne, H., Coelho, L. P., Endo, H., Gasol, J. M., Gregory, A. C., Mahé, F., Rigonato, J., Royo-Llonch, M., Salazar, G., Sanz-Sáez, I., Scalco, E., Soviadan, D., Zayed, A. A., Zingone, A., ... Zinger, L. (2019). Global Trends in Marine Plankton Diversity across Kingdoms of Life. Cell, 179(5), 10841097.e21. https://doi.org/10.1016/j.cell.2019.10.008

Jambeck, J. R., Geyer, R., Wilcox, C., Siegler, T. R., Perryman, M., Andrady, A., Narayan, R., \& Law, K. L. (2015). Plastic waste inputs from microand into the ocean. Science, 347(6223), 768 LP - 771. https://doi.org/10.1126/science.1260352

Kassambara, A. (2020). ggpubr: "ggplot2" Based Publication Ready Plots (R package version 0.2.5). https://doi.org/https://CRAN.R-project.org/package=ggpubr

Katoh, K., \& Standley, D. M. (2013). MAFFT multiple sequence alignment software version 7: Improvements in performance and usability. Molecular Biology and Evolution, 30(4), 772- 
651

652

653

654

655

656

657

658

659

660

661

662

663

664

665

666

667

668

669

670

671

672

673

674

675

676

677

678

679

680

681

780. https://doi.org/10.1093/molbev/mst010

Kennedy, J., Codling, C. E., Jones, B. V., Dobson, A. D. W., \& Marchesi, J. R. (2008). Diversity of microbes associated with the marine sponge, Haliclona simulans, isolated from Irish waters and identification of polyketide synthase genes from the sponge metagenome. Environmental Microbiology, 10(7), 1888-1902. https://doi.org/10.1111/j.1462-2920.2008.01614.x

Kesy, K., Oberbeckmann, S., Kreikemeyer, B., \& Labrenz, M. (2019). Spatial Environmental Heterogeneity Determines Young Biofilm Assemblages on Microplastics in Baltic Sea Mesocosms. Frontiers in Microbiology, 10. https://doi.org/10.3389/fmicb.2019.01665

Kettner, M. T., Oberbeckmann, S., Labrenz, M., \& Grossart, H.-P. (2019). The Eukaryotic Life on Microplastics in Brackish Ecosystems. Frontiers in Microbiology, 10(MAR), 538. https://doi.org/10.3389/fmicb.2019.00538

Kettner, M. T., Rojas-Jimenez, K., Oberbeckmann, S., Labrenz, M., \& Grossart, H.-P. (2017). Microplastics alter composition of fungal communities in aquatic ecosystems. Environmental Microbiology, 19(11), 4447-4459. https://doi.org/10.1111/1462-2920.13891

Kirstein, I. V., Wichels, A., Gullans, E., Krohne, G., \& Gerdts, G. (2019). The plastisphere Uncovering tightly attached plastic "specific" microorganisms. PLoS ONE, 14(4). https://doi.org/10.1371/journal.pone.0215859

Kirstein, I. V., Kirmizi, S., Wichels, A., Garin-Fernandez, A., Erler, R., Löder, M., \& Gerdts, G. (2016). Dangerous hitchhikers? Evidence for potentially pathogenic Vibrio spp. on microplastic particles. Marine Environmental Research, 120, 1-8. https://doi.org/10.1016/j.marenvres.2016.07.004

Kokashvili, T., Whitehouse, C. A., Tskhvediani, A., Grim, C. J., Elbakidze, T., Mitaishvili, N., Janelidze, N., Jaiani, E., Haley, B. J., Lashkhi, N., Huq, A., Colwell, R. R., \& Tediashvili, M. (2015). Occurrence and Diversity of Clinically Important Vibrio Species in the Aquatic Environment of Georgia. Frontiers in Public Health, 3(13). https://doi.org/10.3389/fpubh.2015.00232

Krause, S., Molari, M., Gorb, E. V., Gorb, S. N., Kossel, E., \& Haeckel, M. (2020). Persistence of plastic debris and its colonization by bacterial communities after two decades on the abyssal seafloor. Scientific Reports, 10(1), 1-15. https://doi.org/10.1038/s41598-020-66361-7

Kruskal, J. B. (1964). Nonmetric multidimensional scaling: A numerical method. Psychometrika, 29(2), 115-129. https://doi.org/10.1007/BF02289694

Peer] reviewing PDF | (2021:04:60408:2:0:NEW 6 Aug 2021) 
682 Kruskal, W. H., \& Wallis, W. A. (1952). Use of Ranks in One-Criterion Variance Analysis. 683 Journal of the American Statistical Association, 47(260), 583. 684 https://doi.org/10.2307/2280779

685 Lacerda, A. L. d. F., Proietti, M. C., Secchi, E. R., \& Taylor, J. D. (2020). Diverse groups of fungi 686 are associated with plastics in the surface waters of the Western South Atlantic and the 687 Antarctic Peninsula. Molecular Ecology, 29(19), 1903-1918.

688

689

690

691

692

693

694

695

696

697

698

699

700

701

702

703

704

705

706

707

708

709

710

711

712 https://doi.org/10.111/mec.15444

Laist, D. W. (1997). Impacts of Marine Debris: Entanglement of Marine Life in Marine Debris Including a Comprehensive List of Species with Entanglement and Ingestion Records. In J. M. Coe \& D. B. Rogers (Eds.), Marine Debris: Sources, Impacts, and Solutions (pp. 99-139). Springer New York. https://doi.org/10.1007/978-1-4613-8486-1_10

Law, K. L., Morét-Ferguson, S., Maximenko, N. A., Proskurowski, G., Peacock, E. E., Hafner, J., \& Reddy, C. M. (2010). Plastic Accumulation in the North Atlantic Subtropical Gyre. Science, 329(5996), 1185. https://doi.org/10.1126/science.1192321

Lobelle, D., \& Cunliffe, M. (2011). Early microbial biofilm formation on marine plastic debris. Marine Pollution Bulletin, 62(1), 197-200. https://doi.org/10.1016/j.marpolbul.2010.10.013

Lozupone, C., \& Knight, R. (2005). UniFrac: A new phylogenetic method for comparing microbial communities. Applied and Environmental Microbiology, 71(12), 8228-8235. https://doi.org/10.1128/AEM.71.12.8228-8235.2005

Lusher, A. L., O’Donnell, C., Officer, R., \& O’Connor, I. (2016). Microplastic interactions with North Atlantic mesopelagic fish. ICES Journal of Marine Science, 73(4), 1214-1225. https://doi.org/10.1093/icesjms/fsv241

Mann, H. B., \& Whitney, D. R. (1947). On a Test of Whether one of Two Random Variables is Stochastically Larger than the Other. Annals of Mathematical Statistics, 18(1), 50-60. https://doi.org/10.1214/AOMS/1177730491

Martin, M. (2011). Cutadapt removes adapter sequences from high-throughput sequencing reads. EMBnet.Journal, 17(1), 10. https://doi.org/10.14806/ej.17.1.200

Martiny, J. B. H., Bohannan, B. J. M., Brown, J. H., Colwell, R. K., Fuhrman, J. A., Green, J. L., Horner-Devine, M. C., Kane, M., Krumins, J. A., Kuske, C. R., Morin, P. J., Naeem, S., Øvreås, L., Reysenbach, A. L., Smith, V. H., \& Staley, J. T. (2006). Microbial biogeography: Putting microorganisms on the map. In Nature Reviews Microbiology (Vol. 4, Issue 2, pp. 
713

714

715

716

717

718

719

720

721

722

723

724

725

726

727

728

729

730

731

732

733

734

735

736

737

738

739

740

741

742

743

102-112). https://doi.org/10.1038/nrmicro1341

Mcdonald, J. H. (2014). Handbook of Biological Statistics (3rd ed.). Sparky House Publishing. http://www.biostathandbook.com/index.html

McIlroy, S. J., \& Nielsen, P. H. (2014). The family saprospiraceae. In The Prokaryotes: Other Major Lineages of Bacteria and The Archaea (Vol. 9783642389542, pp. 863-889). SpringerVerlag Berlin Heidelberg. https://doi.org/10.1007/978-3-642-38954-2_138

McMurdie, P. J., \& Holmes, S. (2013). Phyloseq: An R Package for Reproducible Interactive Analysis and Graphics of Microbiome Census Data. PLoS ONE, 8(4), e61217. https://doi.org/10.1371/journal.pone.0061217

Miao, L., Wang, P., Hou, J., Yao, Y., Liu, Z., Liu, S., \& Li, T. (2019). Distinct community structure and microbial functions of biofilms colonizing microplastics. Science of the Total Environment, 650(Pt 2), 2395-2402. https://doi.org/10.1016/j.scitotenv.2018.09.378

Min, K., Cuiffi, J. D., \& Mathers, R. T. (2020). Ranking environmental degradation trends of plastic marine debris based on physical properties and molecular structure. Nature Communications, 11(1), 1-11. https://doi.org/10.1038/s41467-020-14538-z

Muthukrishnan, T., Al Khaburi, M., \& Abed, R. M. M. (2019). Fouling Microbial Communities on Plastics Compared with Wood and Steel: Are They Substrate- or Location-Specific? Microbial Ecology, 78(2), 361-374. https://doi.org/10.1007/s00248-018-1303-0

Muyzer, G., de Waal, E. C., \& Uitterlinden, A. G. (1993). Profiling of complex microbial populations by denaturing gradient gel electrophoresis analysis of polymerase chain reactionamplified genes coding for 16S rRNA. Applied and Environmental Microbiology, 59(3), 695700. https://doi.org/10.1128/AEM.59.3.695-700.1993

O’Toole, G., Kaplan, H. B., \& Kolter, R. (2000). Biofilm formation as microbial development. In Annual Review of Microbiology (Vol. 54, pp. 49-79). Annual Reviews. https://doi.org/10.1146/annurev.micro.54.1.49

Oberbeckmann, S., Kreikemeyer, B., \& Labrenz, M. (2018). Environmental Factors Support the Formation of Specific Bacterial Assemblages on Microplastics. Frontiers in Microbiology, 8 , 2709. https://doi.org/10.3389/fmicb.2017.02709

Oberbeckmann, S. \& Labrenz, M. (2020). Marine Microbial Assemblages on Microplastics: Diversity, Adaptation, and Role in Degradation. Annual Review of Marine Science, 12(1), 209-232. 
744

745

746

747

748

749

750

751

752

753

754

755

756

757

758

759

760

761

762

763

764

765

766

767

768

769

770

771

772

773

774

https://doi.org/10.1146/annurev-marine-010419-010633

Oberbeckmann, S., Loeder, M. G. J., Gerdts, G., \& Osborn, M. A. (2014). Spatial and seasonal variation in diversity and structure of microbial biofilms on marine plastics in Northern European waters. FEMS Microbiology Ecology, 90(2), 478-492. https://doi.org/10.1111/1574-6941.12409

Oberbeckmann, S., Osborn, A. M., \& Duhaime, M. B. (2016). Microbes on a bottle: Substrate, season and geography influence community composition of microbes colonizing marine plastic debris. PLoS ONE, 11(8). https://doi.org/10.1371/journal.pone.0159289

Ogonowski, M., Motiei, A., Ininbergs, K., Hell, E., Gerdes, Z., Udekwu, K. I., Bacsik, Z., \& Gorokhova, E. (2018). Evidence for selective bacterial community structuring on microplastics. Environmental Microbiology, 20(8), 2796-2808. https://doi.org/10.1111/1462-2920.14120

Oksanen, J., Blanchet, F. G., Friendly, M., Kindt, R., Legendre, P., Mcglinn, D., Minchin, P. R., O’hara, R. B., Simpson, G. L., Solymos, P., Henry, M., Stevens, H., Szoecs, E., \& Maintainer, H. W. (2019). Package “vegan” Title Community Ecology Package Version 2.5-6.

Oksanen, J., Blanchet, F. G., Kindt, R., Legendre, P., O’Hara, B., Simpson, G., Solymos, P., Stevens, H., \& Wagner, H. (2010). Vegan: Community Ecology Package. In $R$ package version (Vol. 1).

Pabortsava, K., \& Lampitt, R.S. (2020). High concentrations of plastics hidden beneath the surface of the Atlantic Ocean. Nature Communications, 11, 4073. https://doi.org/10.1038/s41467020-17932-9

Pedregosa, F., Varoquaux, G., Gramfort, A., Michel, V., Thirion, B., Grisel, O., Blondel, M., Müller, A., Nothman, J., Louppe, G., Prettenhofer, P., Weiss, R., Dubourg, V., Vanderplas, J., Passos, A., Cournapeau, D., Brucher, M., Perrot, M., \& Duchesnay, É. (2012). Scikit-learn: Machine Learning in Python. https://arxiv.org/abs/1201.0490

Peeken, I., Primpke, S., Beyer, B., Gütermann, J., Katlein, C., Krumpen, T., Bergmann, M., Hehemann, L., \& Gerdts, G. (2018). Arctic sea ice is an important temporal sink and means of transport for microplastic. Nature Communications, 9(1), 1505. https://doi.org/10.1038/s41467-018-03825-5

Pielou, E. C. (1966). The measurement of diversity in different types of biological collections. Journal of Theoretical Biology, 13(C), 131-144. https://doi.org/10.1016/0022- 
775

776

777

778

779

780

781

782

783

784

785

786

787

788

789

790

791

792

793

794

795

796

797

798

799

800

801

802

803

804

805

5193(66)90013-0

PlasticsEurope. (2020). Plastics - the Facts 2020: An analysis of European plastics production, demand and waste data. https://www.plasticseurope.org/en/resources/publications

Price, M. N., Dehal, P. S., \& Arkin, A. P. (2009). Fasttree: Computing large minimum evolution trees with profiles instead of a distance matrix. Molecular Biology and Evolution, 26(7), 1641-1650. https://doi.org/10.1093/molbev/msp077

Price, M. N., Dehal, P. S., \& Arkin, A. P. (2010). FastTree 2 - Approximately maximum-likelihood trees for large alignments. PLoS ONE, 5(3), e9490. https://doi.org/10.1371/journal.pone.0009490

Inkscape Project (2019). Inkscape (0.92.4). https://inkscape.org

Quast, C., Pruesse, E., Yilmaz, P., Gerken, J., Schweer, T., Yarza, P., Peplies, J., \& Glöckner, F. O. (2013). The SILVA ribosomal RNA gene database project: Improved data processing and web-based tools. Nucleic Acids Research, 41(D1), D590. https://doi.org/10.1093/nar/gks1219

R Core Team (2019). R: A Language and Environment for Statistical Computing (3.6.2). R Foundation for Statistical Computing. https://www.r-project.org/

Roager, L., \& Sonnenschein, E. C. (2019). Bacterial Candidates for Colonization and Degradation of Marine Plastic Debris. Environmental Science \& Technology, 53(20), 11636-11643. https://doi.org/10.1021/acs.est.9b02212

RStudio Team (2016). RStudio: Integrated development environment for R. RStudio, Inc., Boston, MA, http://www.rstudio.com/

Salazar, G., Paoli, L., Alberti, A., Huerta-Cepas, J., Ruscheweyh, H. J., Cuenca, M., Field, C. M., Coelho, L. P., Cruaud, C., Engelen, S., Gregory, A. C., Labadie, K., Marec, C., Pelletier, E., Royo-Llonch, M., Roux, S., Sánchez, P., Uehara, H., Zayed, A. A., ... Wincker, P. (2019). Gene Expression Changes and Community Turnover Differentially Shape the Global Ocean Metatranscriptome. Cell, 179(5), 1068-1083.e21. https://doi.org/10.1016/j.cell.2019.10.014

Shen, M., Zhu, Y., Zhang, Y., Zeng, G., Wen, X., Yi, H., Ye, S., Ren, X., \& Song, B. (2019). Micro(nano)plastics: Unignorable vectors for organisms. Marine Pollution Bullettin, 139, 328-331. https://doi.org/10.1016/j.marpolbul.2019.01.004

Song, J., Jongman-Hochschulz, E., Mauder, N., Imirzalioglu, C., Wichels, A. \& Gerdts, G. (2020). The travelling particles: Investigating microplastics as possible transport vectors for 
806

807

808

809

810

811

812

813

814

815

816

817

818

819

820

821

822

823

824

825

826

827

828

829

830

831

832

833

834

835

836

multidrug resistant E. coli in the Weser estuary (Germany). Science of the total environment, 720, 137603. https://doi.org/10.1016/j.scitotenv.2020.137603

Sussarellu, R., Suquet, M., Thomas, Y., Lambert, C., Fabioux, C., Pernet, M. E. J., Goïc, N. Le, Quillien, V., Mingant, C., Epelboin, Y., Corporeau, C., Guyomarch, J., Robbens, J., PaulPont, I., Soudant, P., \& Huvet, A. (2016). Oyster reproduction is affected by exposure to polystyrene microplastics. Proceedings of the National Academy of Sciences of the United States of America, 113(9), 2430-2435. https://doi.org/10.1073/pnas.1519019113

Urbanek, A. K., Rymowicz, W., \& Mirończuk, A. M. (2018) Degradation of plastics and plasticdegrading bacteria in cold marine habitats. Applied Microbiology and Biotechnology. 102, 7669-7678. https://doi.org/10.1007/s00253-018-9195-y

Vezzulli, L., Brettar, I., Pezzati, E., Reid, P. C., Colwell, R. R., Höfle, M. G., \& Pruzzo, C. (2012). Long-term effects of ocean warming on the prokaryotic community: Evidence from the vibrios. In ISME Journal (Vol. 6, Issue 1, pp. 21-30). Nature Publishing Group. https://doi.org/10.1038/ismej.2011.89

Wickham, H. (2016). ggplot2: Elegant Graphics for Data Analysis. Springer-Verlag New York. https://ggplot2.tidyverse.org

Wright, R. J., Erni-Cassola, G., Zadjelovic, V., Latva, M., \& Christie-Oleza, J. A. (2020). Marine Plastic Debris: A New Surface for Microbial Colonization. Environmental Science and Technology, 54(19), 11657-11672. https://doi.org/10.1021/acs.est.0c02305

Wright, R. J., Langille, M. G. I., \& Walker, T. R. (2020). Food or just a free ride? A meta-analysis reveals the global diversity of the Plastisphere. ISME Journal, 15(3), 789-806. https://doi.org/10.1038/s41396-020-00814-9

Yilmaz, P., Parfrey, L. W., Yarza, P., Gerken, J., Pruesse, E., Quast, C., Schweer, T., Peplies, J., Ludwig, W., \& Glöckner, F. O. (2014). The SILVA and "all-species Living Tree Project (LTP)" taxonomic frameworks. Nucleic Acids Research, 42(D1), D643-D648. https://doi.org/10.1093/nar/gkt1209

Zaiko, A., Schimanski, K., Pochon, X., Hopkins, G. A., Goldstein, S., Floerl, O., \& Wood, S. A. (2016). Metabarcoding improves detection of eukaryotes from early biofouling communities: implications for pest monitoring and pathway management. Biofouling, 32(6), 674-684. https://doi.org/10.1080/089270014.2016.1186165

Zettler, E. R., Mincer, T. J., \& Amaral-Zettler, L. A. (2013). Life in the "Plastisphere": Microbial 
837

838

839

840

841

842

843

844

845

846

847

848

849

850

851

852 from

853 https://blast.ncbi.nlm.nih.gov/Blast.cgi?PROGRAM=blastn\&PAGE TYPE=BlastSearch\&BLAS

854 T SPEC $=\&$ LINK LOC $=$ blasttab\&LAST PAGE=blastp) was employed with the rRNA/ITS

855 database (Sayers et al. 2020).

856 Supplementary Figure S1. Alpha rarefaction curves for all samples before rarefying. Alpha

857 rarefaction curves displaying the absolute number of ASVs present in each sample for all coastal 858 samples.

859 Supplementary Figure S2. Influence of hemisphere on alpha diversity. Violin plots depicting

860 A) Pielou's evenness $(\mathrm{p}=0.018)$ and B) Faith's PD $(\mathrm{p}=0.001)$ of plastic replicates within each 861 hemisphere $(N=29)$ : Northern Hemisphere $(n=14)$, Southern Hemisphere $(n=15)$. Significant 862 results are depicted with symbolic number coding, where * and ** represent Wilcoxon p-values $863 \leq 0.05$ and $\leq 0.01$, respectively. 
864 Supplementary Figure S3: ASV distribution per plastic type per location. All ASVs unique 865 per polymer type were used, regardless of read count, while ASVs overlapping with the glass 866 controls were subtracted. The Venn diagrams were drawn with InteractiVenn (Heberle et al., 867 2015).

868 Supplementary File S1. Qiime2 analysis script. 


\section{Figure 1}

Experimental setup and incubation locations

In this study, bacterial biofilm communities that developed on various substrate types were compared between four incubation locations (A): Cape Verde (Mindelo; $16^{\circ} 53^{\prime} 11.2^{\prime \prime} \mathrm{N}$,

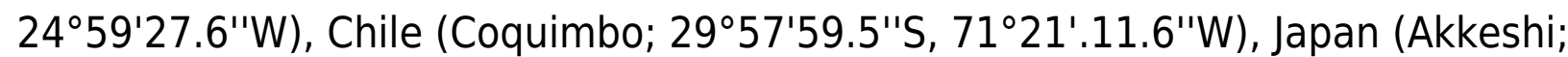
$\left.43^{\circ} 01^{\prime} 14.3^{\prime \prime} \mathrm{N}, 144^{\circ} 50^{\prime} 12.0^{\prime \prime} \mathrm{E}\right)$, and South Africa (Cape Town; 335' $35.89^{\prime \prime} \mathrm{S}$, $\left.18^{\circ} 25^{\prime} 10.15^{\prime \prime} \mathrm{E}\right)$. At each location, four plastic types (HDPE, LDPE, PA, PMMA) were melted onto individual glass microscopy slides, which were then incubated in duplicate for five weeks in the upper one meter of the coastal water column along with plastic-free glass-slide controls. (B) Bacterial biofilm community structure was assessed via amplicon analysis of the V3-V4 region of the 165 rRNA gene.

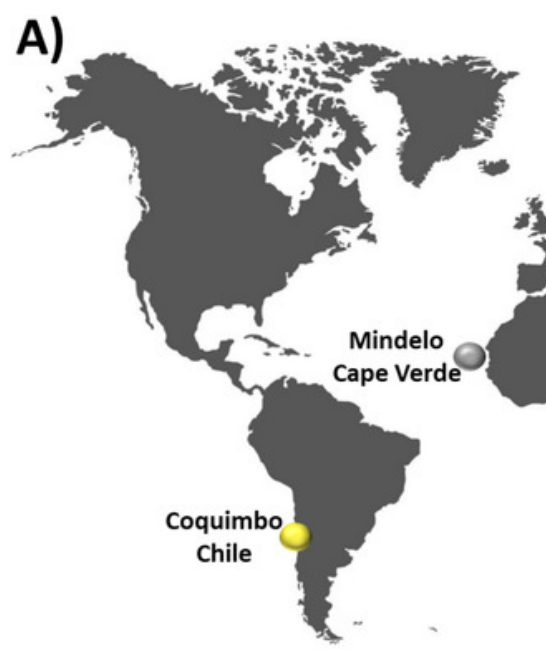

South Africa

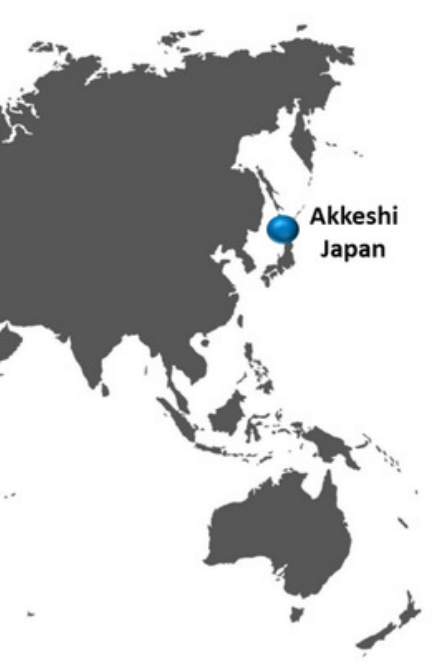

B)

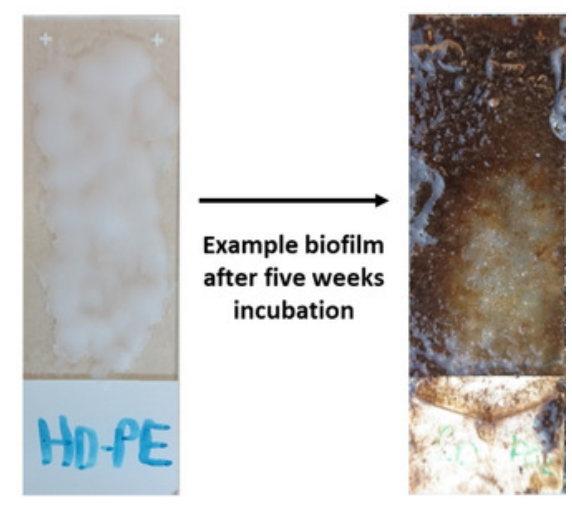


Figure 2

Influence of plastic type on alpha diversity.

Violin plots displaying A) Pielou's evenness (Kruskal-Wallis rank sum test: chi-squared = 5.089, $p=0.278, d f=4$ ) and B) Faith's PD (chi-squared $=2.179, p=0.703, d f=4$ ) within grouped replicates of each substrate type $(N=36)$ : glass-slide control $(n=7), \operatorname{HDPE}(n=7)$, $\operatorname{LDPE}(n=7), \operatorname{PA}(n=7)$, and PMMA $(n=8)$. Non-significant $p$-values are not shown.
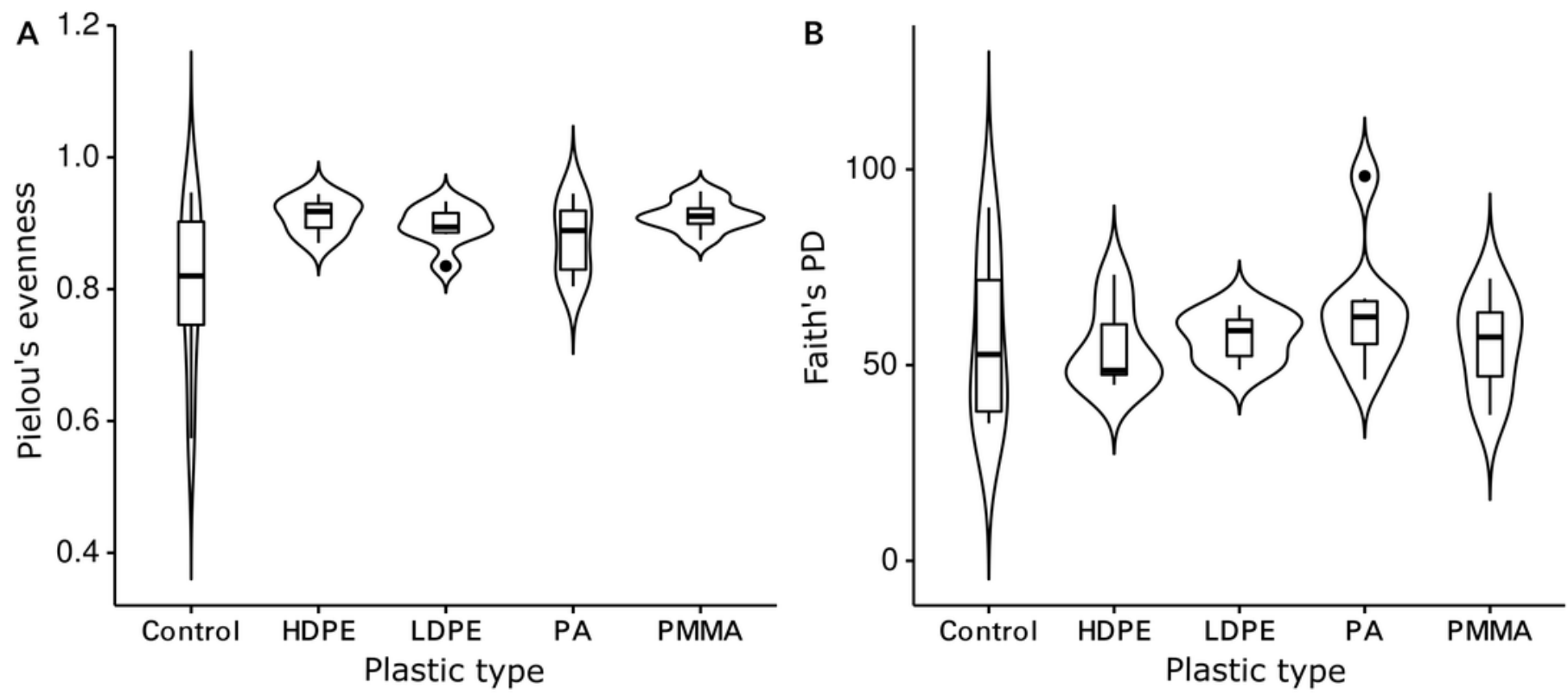
Figure 3

Influence of incubation location on alpha diversity.

Violin plots displaying A) Pielou's evenness (Kruskal-Wallis: chi-squared $=16.663, p<0.001$, $\mathrm{df}=3$ ) and B) Faith's PD (chi-squared $=13.649, \mathrm{p}=0.003, \mathrm{df}=3$ ) of grouped plastic replicates within each study location ( $N=29)$ : Cape Verde $(n=8)$, Chile $(n=7)$, Japan $(n=$ 6), South Africa $(n=8) . *, * *$, and $* * *$ represent $p$-values $\leq 0.05, \leq 0.01$, and $\leq 0.001$, respectively. Non-significant $p$-values are not shown.
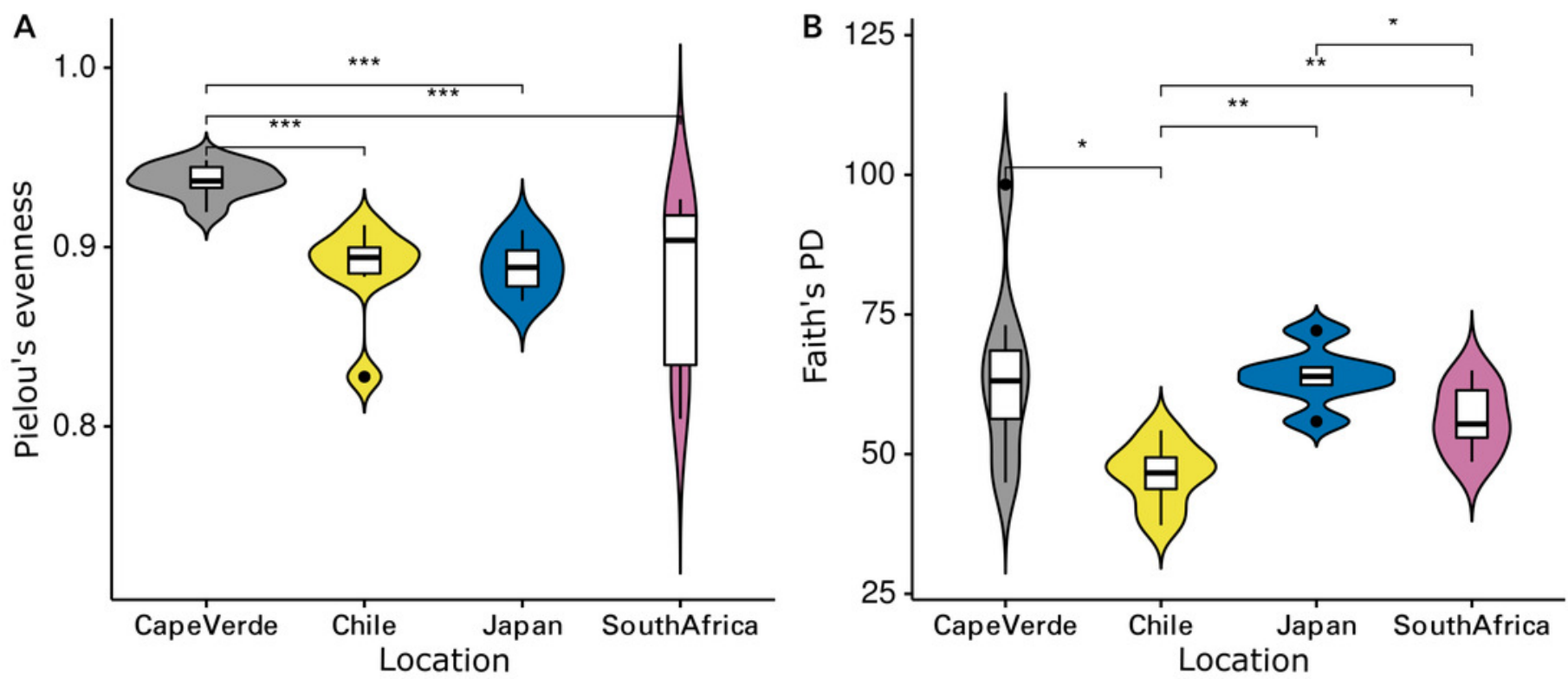


\section{Figure 4}

Incubation location is a primary driver of bacterial community composition.

Nonmetric multidimensional scaling (NMDS) ordination based on an unweighted UniFrac distance matrix of compositionally transformed microbial abundances. Each location (Cape Verde, Chile, Japan, South Africa) is represented by a distinct color and each substrate type (glass-slide control, HDPE, LDPE, PA, PMMA) by a unique symbol. Run stress value: 0.081 .

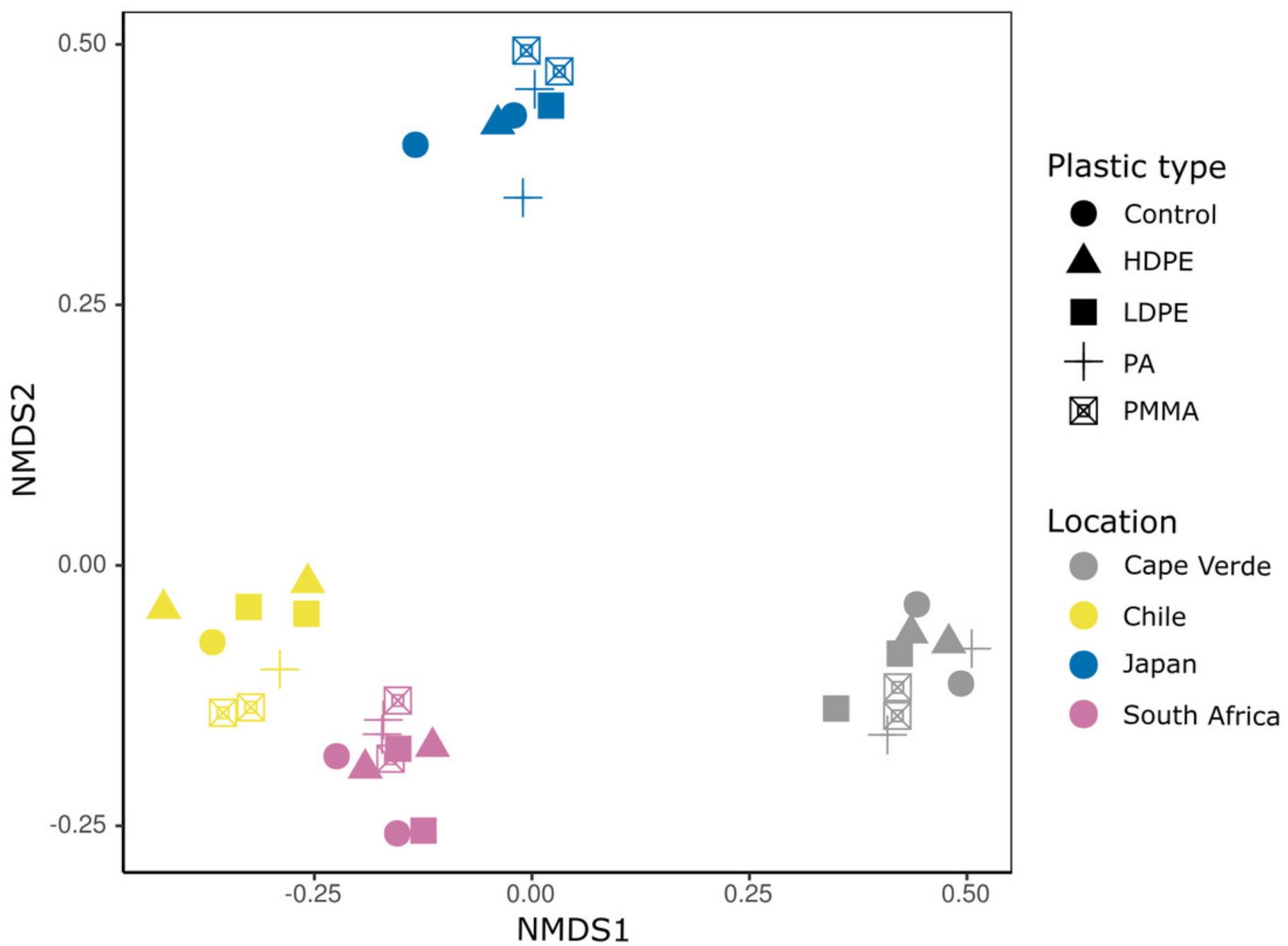




\section{Figure 5}

Phylum level composition of the bacterial communities.

Proteobacteria and Bacteroidota account for the largest proportion of bacterial communities across all samples irrespective of substrate type or incubation location. The bubble plot displays the relative abundance (depicted by size) of phyla that represent more than $0.01 \%$ of the bacterial community structure on at least one substrate type (HDPE, LDPE, PA, PMMA, glass-slide control) in at least one location (Cape Verde, Chile, Japan, South Africa). Phyla are listed in descending order, replicates are faceted by location, and median values are displayed for substrate-types with more than one replicate in each location. *Sample types without replicates. 


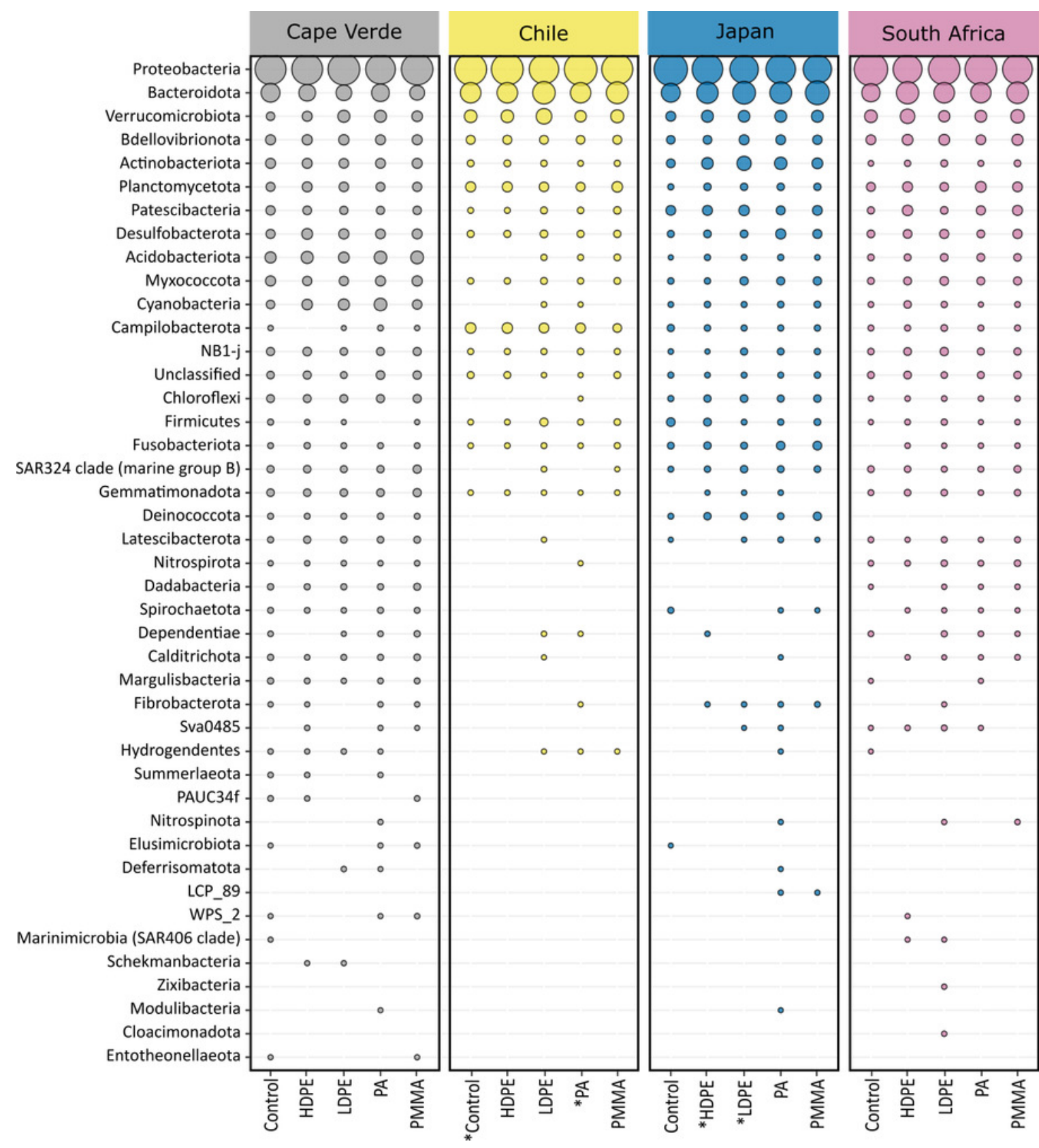

Relative abundance (\%)

70
70
60
50
40
30
20
10
1




\section{Figure 6}

Median percental abundances of recurring bacterial families in Plastisphere communities.

Sunburst chart displaying the median relative abundance of families belonging to the highly prevalent bacterial classes according to the total obtained read counts (447415 reads) from all plastic samples: Bacteroidia, Alphaproteobacteria, and Gammaproteobacteria. Median percental abundances are indicated for all families that reached values above $1.5 \%$. Family names are displayed for taxa that account for more than $0.5 \%$ of the median relative abundance across all plastic replicates. Order names were removed when the overall median abundance was less than $1 \%$ of the total median community composition. 


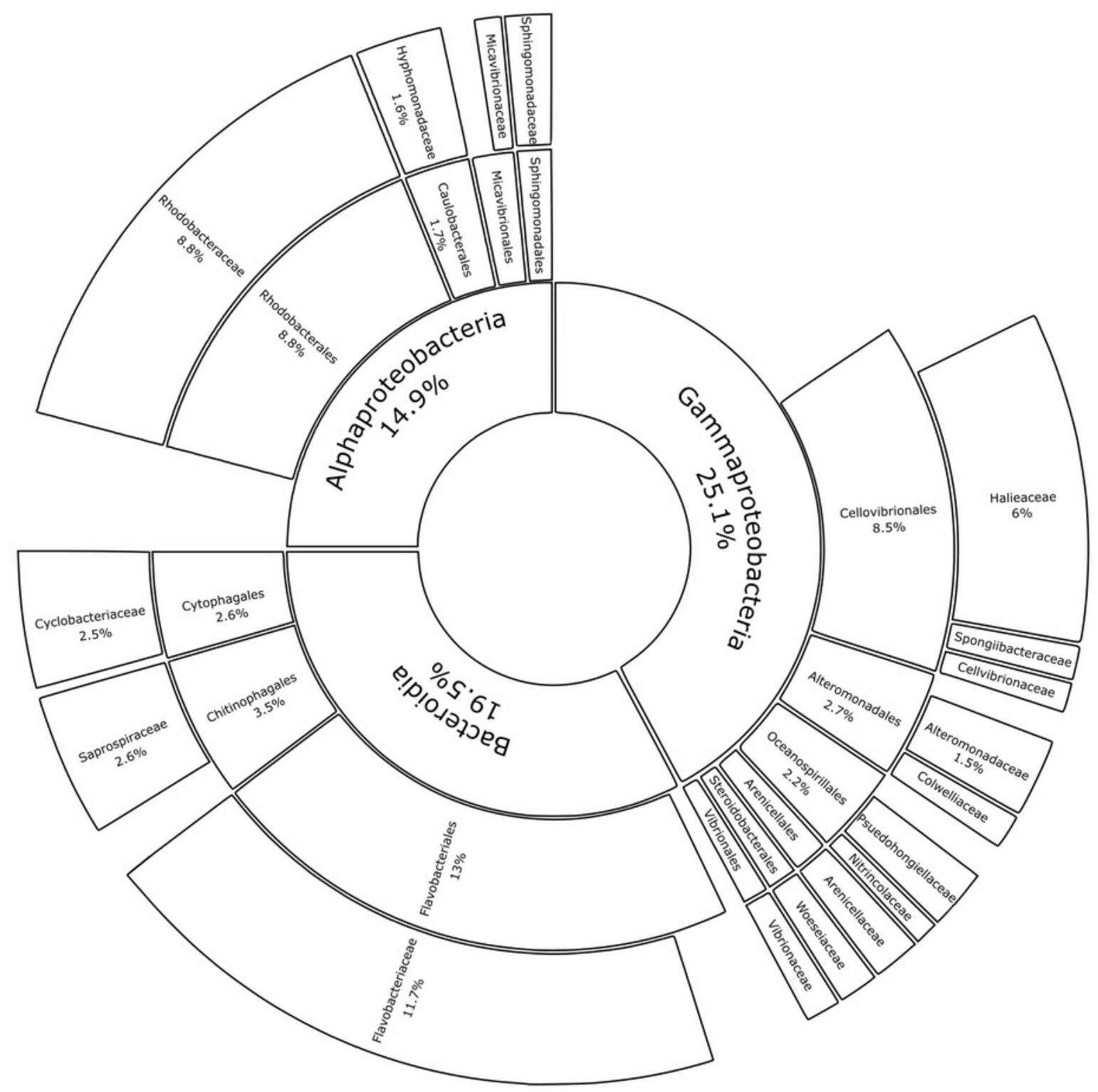




\section{Figure 7}

Shared and distinct ASV counts by incubation location.

Venn diagram depicting distinct and shared ASV counts $(\mathrm{N}=7825)$ of pooled-polymer substrates per location: Cape Verde (29.4 \% distinct), Chile (14.06 \%), Japan (32.0\%), South Africa (20.6\%). ASVs found in biofilms of control samples were removed. This diagram was created using InteractiVenn.net.

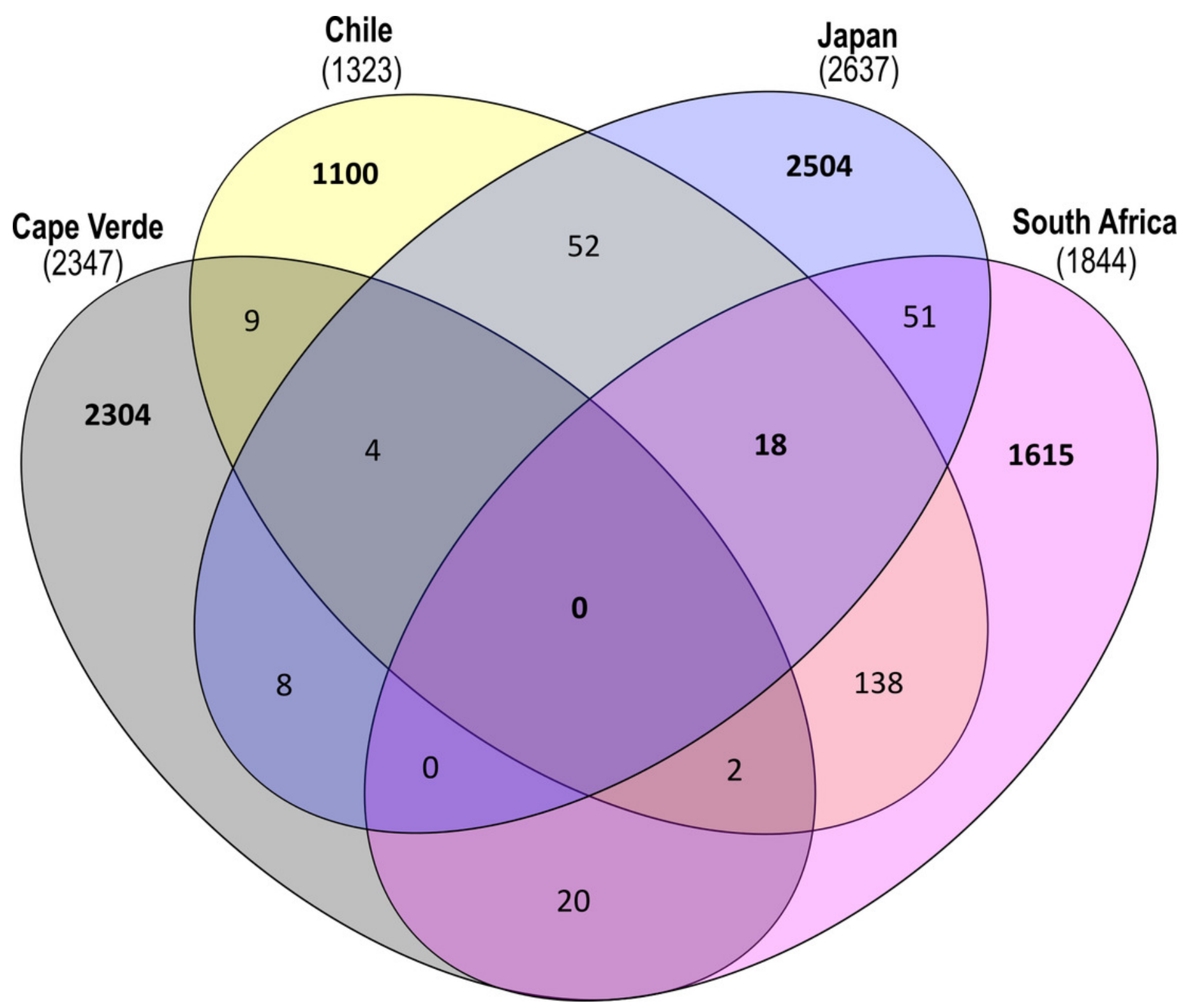




\section{Table 1 (on next page) \\ PERMANOVA Results}

Results of the group-wise PERMANOVA statistical test for substrate type, location, and origin parameters. Pairwise MANOVA tests was completed by location (B), as it had more than two comparable groups. 
1 A)

\begin{tabular}{l|lllll} 
Parameter & Sample size & Permutations & Pseudo-F & p-value & Groups \\
\hline Substrate-type & 36 & 999 & 0.637 & 0.999 & 5 \\
Location & 29 & 999 & 7.516 & 0.001 & 4 \\
Hemisphere & 29 & 999 & 6.082 & 0.001 & 2
\end{tabular}

2 B)

\begin{tabular}{l|l|lllll} 
Location A & Location B & Sample size & Permutations & Pseudo-F & p-value & q-value \\
\hline Cape Verde & Chile & 15 & 999 & 9.337 & 0.001 & 0.001 \\
Cape Verde & Japan & 14 & 999 & 7.354 & 0.001 & 0.001 \\
Cape Verde & South Africa & 16 & 999 & 7.745 & 0.001 & 0.001 \\
Chile & Japan & 13 & 999 & 7.179 & 0.003 & 0.003 \\
Chile & South Africa & 15 & 999 & 6.247 & 0.001 & 0.001 \\
Japan & South Africa & 14 & 999 & 6.940 & 0.001 & 0.001
\end{tabular}

